\title{
Papers of the
}

East West Population Institute, no. 47

\section{The recent fertility decline in the Chiang Mai area of Thailand}

\author{
Tieng Pardthaisong
}




\section{The recent fertility decline in the Chiang Mai area of Thailand}

Tieng Pardthaisong

Number 47 - February 1978

PAPERS OF THE EAST-WEST POPULATION INSTITUTE 
TIENG PARDTHAISONG is a member of the Faculty of Medicine, Chiang Mai University, Thailand.

\section{Library of Congress Cataloging in Publication Data}

Tieng Pardthaisong.

The recent fertility decline in the Chiang Mai area of Thailand.

(Papers of the East-West Population Institute ; no. 47)

Bibliography: p. 35-36.

1. Fertility, Human-Thailand-Chiang Mai (Province) 2. Chiang Mai, Thailand (Province)Statistics, Vital. I. Title. II. Series:

East-West Population Institute. Papers of the East-West Population Institute ; no. 47.

HB1054.55.C48T53 301.32'1'09593 78-4287 


\section{CONTENTS}

Preface vii
Abstract 1

Socio-demographic characteristics of the provinces 2

Evidence of fertility decline based on birth registration 5

Evidence based on censuses $\quad 16$

Evidence based on school data 19

Areal differentials in the Chiang Mai fertility decline $\quad 20$

Discussion 27

Summary and conclusions $\quad 34$

References 35 



\section{TABLES AND FIGURES}

Tables

1 Key socio-demographic characteristics of Chiang Mai Province, three adjacent provinces, and Thailand: 1960 and 19704

2 Percentage of births of third and higher order: Chiang Mai Province, three adjacent provinces, and Thailand, 1961-75 7

3 Registered live births and percentage of first and second births among women aged 25 to 29: Chiang Mai Province, three adjacent provinces, and Thailand, 1961-75 9

4 Estimation of fertility level with Brass technique ( $\mathrm{P} / \mathrm{F}$ ratio): Chiang Mai Province, 196010

5 Age-specific fertility and age-specific marital fertility per 1,000 women: Chiang Mai Province and Thailand, 1960 and $1970 \quad 12$

6 Average number of children ever born, by age of women: Chiang Mai Province and Thailand, 1960 and $1970 \quad 14$

7 Total fertility rates based on all registered births and births to residents only: Chiang Mai Province, 1960-75 15

8 Percentage of children under age 10 in each single age in 1960 and 1970: Thailand, Chiang Mai, and three adjacent provinces 17

9 Ratio of proportions of children under age 10 in each single age for Chiang Mai and three adjacent provinces to the proportions for Thailand in 1960 and 197018

10 Percentage of children born between 1955 and 1967 who were registered in the first grade of 890 primary schools between 1962 and 1974: Chiang Mai Province 20

11 Live births registered in the five study areas of Chiang Mai Province: 1956-75 23

12 Median age of mothers at childbirth for five study areas of Chiang Mai Province: 1956-75 24 
Tables (continued)

13 Seven-year-old pupils (born between 1955 and 1967) registered in the first grade of 890 government schools between 1962 and 1974, by school year and survey study area: Chiang Mai Province 25

14 Ratio of seven-year-olds registered in first grade to number of live births seven years earlier in the five study areas of Chiang Mai Province: 1956-67 26

15 Fertility differentials between $1964-65$ and 1974-75: regions of Thailand 29

16 Proportion of women ever married, by age group: Chiang Mai and Lamphun provinces, 1960 and 197030

17 New acceptors and percentage of acceptors by province in the McCormick Family Planning Programme, 1963-75, and new acceptors in the government program, 1967-75 31

18 New acceptors of McCormick Family Planning Programme as percentage of ever married women aged 15-44, by year and study area 33

Figures

1 Location of Chiang Mai and three adjacent provinces 3

2 Unadjusted crude birth rates based on vital registration data: Chiang Mai Province and Thailand, 1950-73 6

3 Age-specific fertility: Chiang Mai Province, 1960 and 197013

4 Chiang Mai Province divided into five study areas by relative accessibility to Chiang Mai City 21 


\section{PREFACE}

An earlier draft of this paper was prepared for the Seventh Summer Seminar, East-West Population Institute, East-West Center, Honolulu, Hawaii, June 1976. Constructive comments from John Knodel, Ronald H. Gray, William Brass, and John Blacker were particularly useful in revising the original version and are gratefully acknowledged. Helpful comments were also offered by Nicholas H. Wright and Nancy Williamson. Thanks are due to Tongpoon Vicharnrathkan for making available provincial birth registration data, to Suriya Ratanatri for sharing school survey data, to Paipunnee Suwanapratet and her staff at McCormick Family Planning Programme, and to Sootirat Pardthaisong and her staff at Ban Sunkampang School for the collection, extraction, and analysis of birth registration data for Chiang Mai Province. Many thanks are also due to Edwin B. McDaniel for making personnel and resource facilities available, to Louis G. Dooley for continuing encouragement and miscellaneous assistance throughout the project, and to Sutapoj Tansahawat for typing all the analyzed data. I am grateful to Kay Dillon and Sandra Ward for editorial work. Financial support for this research was provided by the Ford Foundation. 

ABSTRACT This paper compares the fertility trend of Chiang Mai Province between 1960 and 1975 with that of Thailand as a whole and with three provinces adjacent to Chiang Mai (Lamphun, Lampang, and Chiang Rai). The analysis uses data from birth registration, from the population censuses of 1960 and 1970, and, for Chiang Mai Province, from registration information for 890 primary schools. Areal differences in birth registration data for Chiang Mai Province over the period 1956-75 are also analyzed. Different patterns of fertility decline are found for Chiang Mai Province, two of the three adjacent provinces, and Thailand as a whole. In Chiang Mai and Lamphun Provinces, there was rapid fertility decline after 1964; total fertility in Chiang Mai Province fell by almost 50 percent between 1960 and 1975. The fertility decline and its relation to several intermediate variables are investigated. Changes in nuptiality patterns between 1960 and 1970 in the Chiang Mai and Lamphun Provinces were insufficient to explain the rapid fertility decline. The rapid decline did, however, coincide to a considerable extent with the progress of family planning programs in these provinces.

In the early 1960s birth rates in Thailand, as in most developing countries, were high and showed little evidence of embarking on the path of decline generally associated with the demographic transition. In contrast, death rates had fallen, especially after World War II, owing to socioeconomic development and the application of modern, relatively inexpensive, imported public health measures and medical technology. The rapid declines in death rates activated the large growth potential inherent in the high birth rates. It was not until 1958, when a World Bank Economic Commission asserted that the high rate of population growth was adversely affecting Thailand's development efforts, that the Ministry of Public Health and other interested governmental and private agencies began activities in the field of family planning, quietly and with many restraints. Finally in March 1970 the Thai Cabinet, after having considered the population question on many occasions since 1959, declared a formal National Population Policy (Thailand, Ministry of Public Health, 1972a). This policy was to reduce the population growth rate, through the establishment of family planning programs, from more than 3 percent per annum to 2.5 percent by the end of 1976. 
There is mounting evidence that fertility in Thailand has recently started to decline, although the precise extent of the decline is disputed. Within the national average, however, there appear to be substantial regional differences in fertility trends. The Northern Region, particularly the area around Chiang Mai, seems to have experienced a remarkably rapid and substantial fertility reduction. The purposes of this paper are:

1. To document the dramatic fertility decline that has apparently taken place in Chiang Mai Province between 1960 and 1975 , using evidence from several independent sources. Although each source of evidence has problems associa ted with it, together they yield a fairly consistent picture of a dramatic decline in fertility that is among the fastest observed in the recent experience of less developed countries.

2. To compare the fertility trends of Chiang Mai and three adjacent provinces to those of Thailand as a whole.

3. To evaluate the role that family planning programs have played in the fertility decline.

\section{SOCIO-DEMOGRAPHIC CHARACTERISTICS OF THE PROVINCES}

Chiang Mai Province, with an area of 22,993 square kilometers, is the seventh largest of Thailand's 71 provinces and the second largest province in Northern Thailand (Figure 1). Its central city, Chiang Mai, is 800 kilometers from Bangkok. The terrain is mountainous with interspersed plateaus and valleys. Transportation between population centers, primarily in the valleys and plateaus, varies in quality from excellent to very poor. The province had a population of 798,483 in 1960 and 1,026,450 in 1970, the difference representing an average annual growth rate of 2.6 percent (Table 1). Population density in 1970 was 47 persons per square kilometer (compared with the national average of 67), but this figure is not very meaningful because the population is not evenly dispersed throughout the province. Almost 92 percent of the province's inhabitants in 1970 were rural, compared with 87 percent for the country as a whole. The proportion of women aged 15-44 who had four or more years of education increased from 40 to 64 percent between 1960 and 1970 .

Three of the provinces adjacent to Chiang Mai are Lamphun, Lampang, and Chiang Rai. The terrain of these provinces, like that of Chiang Mai, is mountainous. Of the three provinces, Chiang Rai is the largest in area and population, comparable to Chiang Mai, and Lam- 
FIGURE 1 Location of Chiang Mai and three adjacent provinces

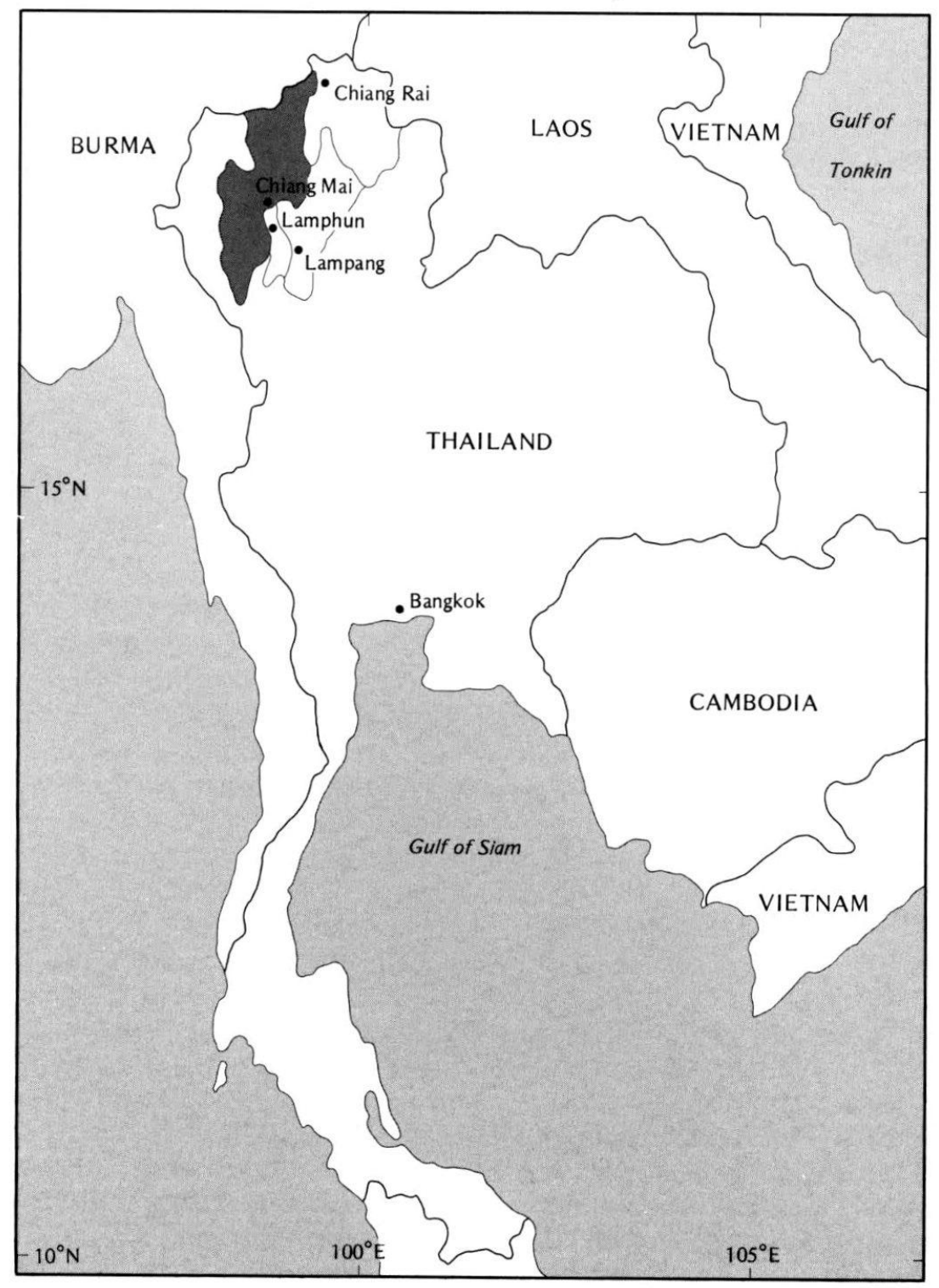


TABLE 1 Key socio-demographic characteristics of Chiang Mai Province, three adjacent provinces, and Thailand: 1960 and 1970

\begin{tabular}{|c|c|c|c|c|c|}
\hline \multirow[b]{2}{*}{ Characteristics } & \multirow{2}{*}{$\begin{array}{l}\text { Chiang } \\
\text { Mai }\end{array}$} & \multicolumn{3}{|c|}{ Three adjacent provinces } & \multirow[b]{2}{*}{ Thailand } \\
\hline & & Lamphun & Lampang & Chiang Rai & \\
\hline \multicolumn{6}{|l|}{ Population size } \\
\hline 1960 & 798,483 & 249,820 & 471,699 & 811,711 & $26,257,916$ \\
\hline 1970 & $1,026,450$ & 310,836 & 583,378 & $1,111,607$ & $34,397,374$ \\
\hline $\begin{array}{l}\text { Average popula } \\
\text { growth rate per } \\
\text { annum, 1960-- } \\
\text { (percentage) }\end{array}$ & 2.6 & 2.1 & 2.1 & 3.1 & 2.8 \\
\hline \multicolumn{6}{|c|}{$\begin{array}{l}\text { Percentage of popu- } \\
\text { lation in municipal } \\
\text { area }\end{array}$} \\
\hline 1960 & 8.2 & 4.2 & 7.7 & 4.2 & 12.5 \\
\hline 1970 & 8.2 & 3.6 & 6.9 & 3.1 & 13.2 \\
\hline \multicolumn{6}{|c|}{$\begin{array}{l}\text { Percentage of } \\
\text { women, ages } 15-44 \text {, } \\
\text { with } 4 \text { or more years } \\
\text { of schooling }\end{array}$} \\
\hline 1960 & 40.2 & 46.2 & 34.3 & 25.8 & 56.6 \\
\hline 1970 & 63.6 & 71.5 & 58.0 & 51.0 & 76.3 \\
\hline
\end{tabular}

SOURCE: Thailand, Office of Prime Minister $(1962,1973)$.

phun is the smallest. Population growth in Chiang Rai during the 1960s was even more rapid than in Chiang Mai (3.1 percent a year, on the average), but in Lamphun and Lampang it was slower (2.1 percent). Transportation between population centers in these provinces varies from excellent to very poor, as in Chiang Mai Province.

The level of female education varies from province to province. Lamphun had the highest levels, whereas Chiang Rai had the lowest in both 1960 and 1970. Female education in all four northern provinces is less prevalent than in Thailand as a whole, but since 1960 it has improved dramatically.

The medical service structure is similar in the four provinces. It consists of a provincial hospital, first class and second class health centers, and auxiliary nurse midwife stations. But Chiang Mai Province has a large, higher quality "provincial" hospital, which is part of Chiang Mai University, and also has more private hospitals than the other prov- 
inces. Since most of the people of Lamphun Province live in the same wide valley as the majority of the Chiang Mai population, there is common transportation between the population centers. This ease of access for the Lamphun population to the same centers serving the Chiang Mai population is especially important with regard to access to family planning. Such sharing is not possible for people in Chiang Rai and Lampang, whose access is limited by high mountains.

Two sources of data are available for all four study regions: birth registration data for 1960-75 (Thailand, Ministry of Public Health, undated), and population censuses for 1960 and 1970 (Thailand, Office of Prime Minister, 1962, 1973). Additional sources of data for Chiang Mai Province consist of birth registration by month and by amphoe (district) between 1956 and 1975 (Chiang Mai Province, Office of Health, undated), and school registration for pupils in the first grade of all government schools between 1962 and 1974. Also cited is evidence from a dual record system, the Survey of Population Change (Thailand, Office of Prime Minister, 1970, 1977), in the Northern Region of Thailand.

\section{EVIDENCE OF FERTILITY DECLINE BASED ON BIRTH REGISTRATION}

Considerable evidence exists in the birth registration data of northern Thailand that Chiang Mai and its neighboring provinces experienced a rapid fertility decline over the fifteen-year period beginning in 1960 . Using these data, this paper will examine changes in the crude birth rate, the ratio of higher order births to total births, the number of first and second births among women in the age group 25-29, the age pattern of fertility, and the total fertility rate.

\section{The crude birth rate}

Figure 2 shows crude birth rates based on birth registration data from 1950 to 1973 for the Chiang Mai population (Chiang Mai, Office of Health, 1976) and for Thailand as a whole (Thailand, Ministry of Public Health, 1972c). That registration problems appear to have plagued the Chiang Mai data at least until 1954 is suggested by the rapid rise in the recorded birth rate during the prior years. In 1955 the Chiang Mai crude birth rate was 41 per 1,000 , the highest observed in the province during the whole period. From 1955 to 1960 , the crude birth rate remained fairly constant at between 38 and 40 per 1,000. After 1960, it declined in three stages: from 1960 to 1964, it declined slowly from 38.5 to 34.4 per 1,000 ; from 1964 to 1969 , it declined rapidly from 


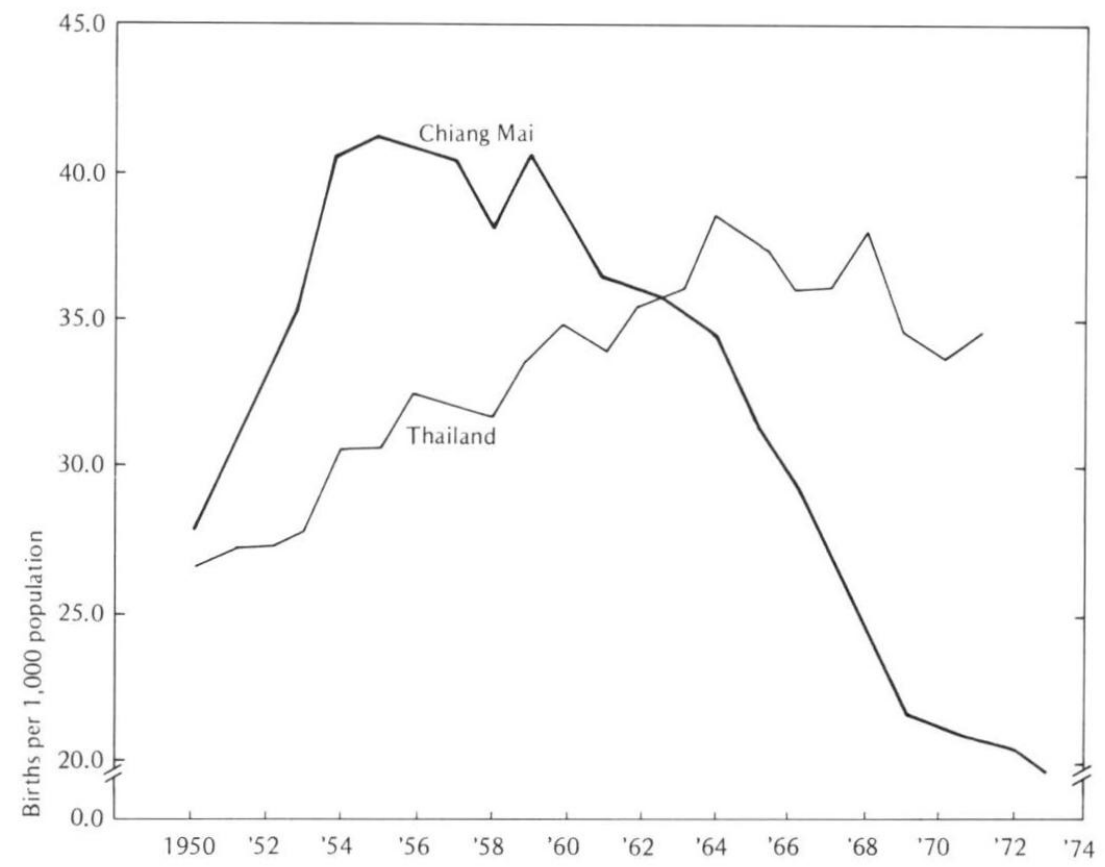

FIGURE 2 Unadjusted crude birth rates based on vital registration data: Chiang Mai Province and Thailand, 1950-73

34.4 to 21.7 per 1,000 ; and, from 1969 to 1973 , it declined very slowly from 21.7 to 19.2 . By comparison, the crude birth rate for the whole Kingdom of Thailand did not reach its highest level until nearly ten years after Chiang Mai's peak. In 1964 it was 38.5 per 1,000. Undoubtedly, the rising Thai birth rate is largely a reflection of improvements in registration. After 1964 the crude birth rate for the kingdom as a whole declined very slowly to 34.5 in 1971 .

The comparison of birth registration data for Chiang Mai Province with Thailand as a whole seems to suggest that: (a) birth registration in Chiang Mai Province improved at least ten years before it improved for Thailand as a whole, and (b) the crude birth rate of the Chiang Mai population declined much sooner and much more rapidly than that of Thailand as a whole. There is no evidence to suggest that the decline in the crude birth rate for Chiang Mai during the 1960s and 1970s was an artifact produced by a deterioration in the completeness of the registration system. 


\section{High order births}

All else being equal, a decline in the ratio of higher order births to total births suggests a reduction in fertility. Fertility can be expected to decline most among women who already have the number of children they desire; women of higher parity, of course, are more likely to be in this category. In Chiang Mai, the proportion of third and higher order births increased slightly between 1961 and 1964 (from 58 to 60 percent), and thereafter declined markedly (to 24 percent in 1975). (See Table 2.) Lamphun Province showed the same trend as Chiang Mai. In Lampang Province there was a definite decline in the percentage of third and higher order births, but it was less dramatic and occurred later than in Chiang Mai. This pattern of decline did not occur in Chiang Rai Province throughout the period of the study.

The proportion of births of third and higher order could have been

TABLE 2 Percentage of births of third and higher order: Chiang Mai Province, three adjacent provinces, and Thailand, 1961-75

\begin{tabular}{|c|c|c|c|c|c|}
\hline \multirow[b]{2}{*}{ Year } & \multirow[b]{2}{*}{ Chiang Mai } & \multicolumn{3}{|c|}{ Three adjacent provinces } & \multirow[b]{2}{*}{ Thailand } \\
\hline & & Lamphun & Lampang & Chiang Rai & \\
\hline 1961 & 57.5 & 55.8 & 64.4 & 63.2 & 59.7 \\
\hline 1962 & 58.6 & 62.4 & 61.6 & 63.7 & 60.5 \\
\hline 1963 & 59.4 & 66.4 & 61.0 & 63.0 & 60.1 \\
\hline 1964 & 60.3 & 67.2 & 62.8 & 64.7 & 61.2 \\
\hline 1965 & 58.8 & 65.2 & 62.8 & 64.5 & 61.1 \\
\hline 1966 & 58.9 & 64.4 & 64.3 & 62.7 & 60.4 \\
\hline 1967 & 56.7 & 62.0 & 63.3 & 63.4 & 60.1 \\
\hline 1968 & 55.9 & 58.4 & 62.4 & 62.3 & 59.4 \\
\hline 1969 & 51.2 & 57.5 & 60.1 & 56.8 & 58.5 \\
\hline 1970 & 48.4 & 53.8 & 59.0 & 57.6 & 58.5 \\
\hline 1971 & 45.2 & 51.4 & 54.5 & 60.2 & 57.6 \\
\hline 1972 & 40.2 & 47.1 & 48.7 & 67.7 & 54.9 \\
\hline 1973 & 35.9 & 43.5 & 44.7 & 65.5 & 53.3 \\
\hline 1974 & 30.9 & 35.7 & 41.6 & 65.7 & 51.2 \\
\hline 1975 & 24.3 & 30.6 & 35.0 & 65.8 & u \\
\hline
\end{tabular}

u-unavailable.

SOURCE: Thailand, Ministry of Public Health (1972c). 
influenced by changes in the age structure of the population. It is therefore of interest to examine the birth distribution for particular age groups.

\section{First and second births among women aged 25-29}

Focusing on women in the high-fertility age group of 25-29 as an illustration of age-specific results (Pearl, 1937), Table 3 reveals that the number of registered live births to these women in Chiang Mai, Lamphun, and Lampang decreased substantially between 1961 and 1975. In Chiang Mai Province the decline was fairly steady. By contrast, there were only marginal declines in the total number of registered live births in Chiang Rai and Thailand as a whole. The patterns of decline in live births for Chiang Mai, the three adjacent provinces, and Thailand are similar to the patterns in the proportion of births that were of third and higher order. More noteworthy, the proportion of first and second order births among women aged 25 to 29 in Chiang Mai steadily increased between 1968 and 1975 (from 37 to 71 percent), suggesting that more and more women in this age group were having families of only one or two children.

\section{Age pattern of fertility}

For Chiang Mai Province, registration data are available on the number of live births by age of mother in 1960 and 1970. Parity distributions by age of woman in 1960 and 1970 were obtained from the population censuses of those years. With these data and a technique developed by Brass (1968), the pattern of age-specific fertility rates can be determined as follows: Recorded births in the past year are obtained from the vital registration system and the level of fertility is estimated from the mean number of children ever born as reported by younger women in the census. As a cohort of women moves through life, the mean number of children ever born by exact age of the women should equal the cumulative total of age-specific fertility rates experienced by the cohort up to that age. If the fertility of the population has been constant, the age-specific birth rates of each cohort should be approximately the same as current rates. The ratio of the retrospective data on children ever born, derived from the census, to the cumulative fertility rates based on the registration data for the young females $(\mathrm{P} / \mathrm{F}$ ratios) gives a correction factor that can be applied to the current registered rates at all ages to adjust the fertility for underregistration. Basic assumptions for applying the technique are that underregistration is the same for all ages, the number of children ever born is reported with 
TABLE 3 Registered live births and percentage of first and second births among women aged 25 to 29: Chiang Mai Province, three adjacent provinces, and Thailand, 1961-75

\begin{tabular}{|c|c|c|c|c|c|c|c|c|c|c|}
\hline \multirow[b]{2}{*}{ Year } & \multicolumn{5}{|c|}{ Registered live births } & \multicolumn{5}{|c|}{ Percentage of first and second births } \\
\hline & $\begin{array}{l}\text { Chiang } \\
\text { Mai }\end{array}$ & Lamphun & Lampang & $\begin{array}{l}\text { Chiang } \\
\text { Rai }\end{array}$ & Thailand & $\begin{array}{l}\text { Chiang } \\
\text { Mai }\end{array}$ & Lamphun & Lampang & $\begin{array}{l}\text { Chiang } \\
\text { Rai } \\
\end{array}$ & Thailand \\
\hline 1961 & 8,068 & 2,673 & 4,180 & 8,878 & 253,566 & 43.1 & 46.3 & 32.6 & 30.2 & 37.2 \\
\hline 1962 & 7,814 & 2,822 & 3,427 & 9,221 & 265,988 & 43.9 & 35.8 & 36.9 & 30.9 & 37.3 \\
\hline 1963 & 7,752 & 2,653 & 3,278 & 9,102 & 277,504 & 43.9 & 34.3 & 38.9 & 32.5 & 37.9 \\
\hline 1964 & 7,167 & 2,516 & 4,063 & 9,108 & 299,972 & 42.4 & 31.7 & 34.7 & 29.5 & 37.0 \\
\hline 1965 & 6,381 & 2,219 & 3,535 & 8,769 & 289,760 & 42.0 & 31.5 & 32.9 & 28.7 & 36.5 \\
\hline 1966 & 6,084 & 2,076 & 3,431 & 7,987 & 274,279 & 39.2 & 33.0 & 31.5 & 30.5 & 36.4 \\
\hline 1967 & 5,190 & 1,686 & 3,066 & 7,262 & 258,641 & 39.2 & 33.3 & 31.0 & 29.7 & 36.5 \\
\hline 1968 & 4,717 & 1,600 & 3,034 & 7,050 & 264,785 & 37.2 & 38.9 & 32.7 & 28.0 & 36.9 \\
\hline 1969 & 4,136 & 1,372 & 2,719 & 7,360 & 237,881 & 42.6 & 38.7 & 31.7 & 34.0 & 37.2 \\
\hline 1970 & 3,754 & 1,218 & 2,424 & 4,973 & 247,259 & 43.3 & 42.0 & 34.3 & 34.3 & 37.0 \\
\hline 1971 & 3,630 & 1,448 & 2,506 & 5,825 & 233,877 & 46.1 & 41.1 & 34.4 & 30.0 & 37.3 \\
\hline 1972 & 3,718 & 1,295 & 2,424 & 6,317 & 249,262 & 52.1 & 43.6 & 41.6 & 21.8 & 36.6 \\
\hline 1973 & 3,616 & 1,316 & 2,227 & 6,468 & 243,405 & 56.9 & 45.1 & 45.2 & 29.4 & 42.2 \\
\hline 1974 & 3,804 & 923 & 2,157 & 6,146 & 247,707 & 62.5 & 57.8 & 48.3 & 37.9 & 44.8 \\
\hline 1975 & 3,941 & 876 & 1,948 & 6,393 & $\mathrm{u}$ & 70.5 & 62.4 & 54.9 & 30.6 & $\mathrm{u}$ \\
\hline
\end{tabular}

u-unavailable.

SOURCE: Thailand, Ministry of Public Health (1972c). 
good accuracy by younger women, and women who died had the same fertility as those who survived.

Results of the application of this method to the Chiang Mai population data of 1960 are shown in Table 4 . The $\mathrm{P} / \mathrm{F}$ ratios show a consistent result, around 1.0 for all age groups. Since Chiang Mai and Thailand have a "late" pattern of marriage and childbearing, it is reasonable to select as the correction factor the average of the $\mathrm{P} / \mathrm{F}$ ratios for women in the 20-24 and 25-29 age groups, which is 1.0124. This figure implies that only about 1.2 percent of the births in Chiang Mai Province in 1960 were unregistered. Total fertility calculated from birth registration data was 5.2 , adjusted to 5.3 by the correction. The results of this technique provide an encouraging assessment of the completeness of birth registration in Chiang Mai Province by 1960. They suggest that from 1960 on, the unadjusted registration data for Chiang Mai can be used without much risk of serious error, provided there was no significant deterioration of registration after 1960 (and there is no reason to suspect there was). This is fortunate since it would be inappropriate to apply this technique to the 1970 data for Chiang Mai in view of the evidence that fertility fell sharply between 1960 and 1970.

Unfortunately, birth registration in Thailand as a whole appears to be substantially less complete than in Chiang Mai. Applying the Brass technique to national-level data for both 1960 and 1970, Rungpitarangsi (1974) estimated that 33 percent of all births in 1960 and 28

TABLE 4 Estimation of fertility level with Brass technique (P/F ratio): Chiang Mai Province, 1960

\begin{tabular}{|c|c|c|c|c|c|}
\hline Age group & $\begin{array}{l}\text { Age-specific fertility } \\
\text { from registration } \\
\left(f_{i}\right)\end{array}$ & $F_{i}$ & $P_{i}$ & $P_{i} / F_{i}$ & $\begin{array}{l}\text { Adjusted } \\
f_{i}\end{array}$ \\
\hline $15-19$ & 0.0649 & 0.1145 & 0.1079 & 0.9424 & 0.0657 \\
\hline $20-24$ & 0.2450 & 1.0121 & 1.0097 & 0.9976 & 0.2480 \\
\hline $25-29$ & 0.2480 & 2.2925 & 2.3553 & 1.0274 & 0.2511 \\
\hline $30-34$ & 0.2178 & 3.4656 & 3.6171 & 1.0437 & 0.2205 \\
\hline $35-39$ & 0.1703 & 4.4279 & 4.5385 & 1.0250 & 0.1724 \\
\hline $40-44$ & 0.0777 & 4.9990 & 5.2328 & 1.0468 & 0.0787 \\
\hline $45-49$ & 0.0173 & 5.1919 & 5.3899 & 1.0381 & 0.0175 \\
\hline $\begin{array}{l}\text { Total } \\
\text { fertility }\end{array}$ & 5.21 & & & & 5.27 \\
\hline
\end{tabular}


percent in 1970 were unregistered. Rungpitarangsi's results for 1970 must be interpreted with caution since the assumption of constant fertility appears to be no longer valid by the end of the decade, although, at the national level, the extent of fertility decline was probably very moderate.

Age-specific fertility rates for Chiang Mai and Thailand as a whole in 1960 and 1970 are presented in Table 5, and are shown graphically for Chiang Mai in Figure 3. Unadjusted rates are shown for Chiang Mai for both dates since, as indicated above, the registration data appear to be relatively complete. For Thailand the adjusted rates as calculated by Rungpitarangsi (1974) are used because underregistration appears to be a serious problem at the national level in both years. The age pattern of marital fertility is also shown, as is the Coale-Trussell index of fertility control $(\mathrm{m})$, which measures the extent of fertility control implicit in the age structure of marital fertility. The higher the value of $m$, the more birth control is implicit in the fertility structure (Coale and Trussell, 1974; Knodel, 1977).

From Table 5 it can be seen, first, that fertility declined much more in Chiang Mai Province than in Thailand as a whole between 1960 and 1970. According to this analysis, the total fertility rate fell by 40 percent in Chiang Mai during the decade but only by 4 percent in Thailand. Indeed, as Rungpitarangsi (1974) notes, the reduction of fertility for Thailand as a whole should be viewed with caution owing to the nature of the estimates. Second, fertility in Chiang Mai decreased more among older than among younger women, a pattern typical of the early stage of demographic transition. Older women are more likely than younger women to have reached their preferred family size, and thus are more strongly motivated to prevent further births. Third, the CoaleTrussell index of fertility control shows a steep rise in the extent of control implicit in the age structure of marital fertility during the decade. In sum, the age pattern of fertility change in Chiang Mai is consistent with the pattern typically associated with the transition from high to low levels of fertility.

One bit of contrary evidence should be mentioned in connection with the present discussion. A comparison of the average number of children ever born for Chiang Mai Province based on the 1960 and 1970 censuses shows very little change (Table 6). In view of the substantial fertility decline documented in the data already presented and in the additional data to be presented below, one would expect a greater reduction in the number of children ever born. One reason for the inconsistency, no doubt, is the difference in the way age was re- 
TABLE 5 Age-specific fertility and age-specific marital fertility per 1,000 women: Chiang Mai Province and Thailand, 1960 and 1970

\begin{tabular}{|c|c|c|c|c|c|c|c|c|c|c|c|c|}
\hline \multirow[b]{3}{*}{$\begin{array}{l}\text { Age } \\
\text { group }\end{array}$} & \multicolumn{6}{|c|}{ Age-specific fertility } & \multicolumn{6}{|c|}{ Age-specific marital fertility ${ }^{\mathrm{a}}$} \\
\hline & \multicolumn{3}{|c|}{$\begin{array}{l}\text { Chiang Mai (unadjusted } \\
\text { for underregistration) }\end{array}$} & \multicolumn{3}{|c|}{$\begin{array}{l}\text { Thailand (adjusted } \\
\text { for underregistration) }\end{array}$} & \multicolumn{3}{|c|}{ Chiang Mai } & \multicolumn{3}{|c|}{ Thailand } \\
\hline & 1960 & 1970 & $\begin{array}{l}\text { Percent- } \\
\text { age of } \\
\text { change }\end{array}$ & 1960 & 1970 & $\begin{array}{l}\text { Percent- } \\
\text { age of } \\
\text { change }\end{array}$ & 1960 & 1970 & $\begin{array}{l}\text { Percent- } \\
\text { age of } \\
\text { change }\end{array}$ & 1960 & 1970 & $\begin{array}{l}\text { Percent- } \\
\text { age of } \\
\text { change }\end{array}$ \\
\hline $15-19$ & 65 & 55 & -15 & 53 & 65 & +23 & 365 & 302 & -17 & 424 & 371 & -13 \\
\hline $20-24$ & 245 & 189 & -23 & 263 & 282 & +7 & 383 & 308 & -20 & 466 & 487 & +5 \\
\hline $25-29$ & 248 & 146 & -41 & 318 & 300 & -6 & 300 & 177 & -41 & 399 & 379 & -5 \\
\hline $30-34$ & 218 & 109 & -50 & 279 & 255 & -9 & 247 & 123 & -50 & 324 & 297 & -8 \\
\hline $35-39$ & 170 & 83 & -52 & 234 & 207 & -12 & 194 & 93 & -52 & 271 & 238 & -12 \\
\hline $40-44$ & 78 & 40 & -49 & 116 & 106 & -9 & 92 & 46 & -50 & 140 & 125 & -15 \\
\hline $45-49$ & 17 & 5 & -71 & 28 & 27 & -4 & 21 & 6 & -71 & 36 & 34 & -3 \\
\hline $\begin{array}{l}\text { Total } \\
\text { fertility } \\
\text { rate }\end{array}$ & 521 & 314 & -40 & 646 & 621 & -4 & & & & & & \\
\hline$m$ index $^{b}$ & & & & & & & .34 & .98 & & .14 & .32 & \\
\hline
\end{tabular}

a Estimated by dividing the age-specific rates by the proportion currently married.

b The $m$ index is the Coale-Trussell index of fertility control and has been calculated as the average value of $m$ for age groups $25-29$ to 45-49. See Knodel (1977) and Coale and Trussell (1974) for discussion of $m$.

SOURCE: Rungpitarangsi, Vichai (1974). 
FIGURE 3 Age-specific fertility: Chiang Mai Province, 1960 and 1970

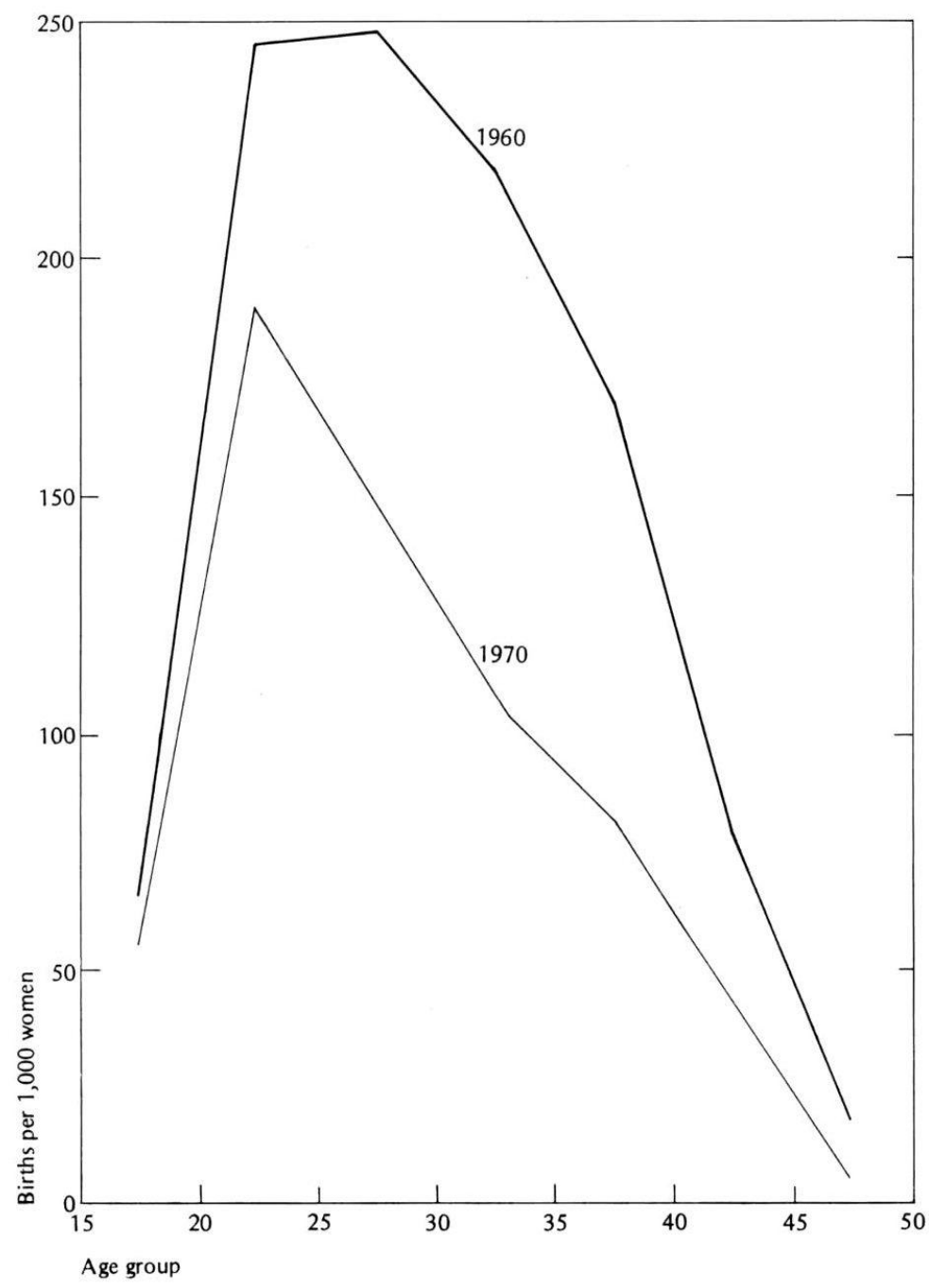


TABLE 6 Average number of children ever born, by age of women: Chiang Mai Province and Thailand, 1960 and 1970

\begin{tabular}{lllllllll}
\hline & \multicolumn{3}{l}{ Chiang Mai Province } & & \multicolumn{2}{l}{ Thailand } \\
Age group & 1960 & 1970 & $\begin{array}{l}\text { Percentage } \\
\text { of change }\end{array}$ & & 1960 & 1970 & $\begin{array}{c}\text { Percentage } \\
\text { of change }\end{array}$ \\
\hline $15-19$ & 0.11 & 0.13 & +0.02 & & 0.07 & 0.13 & +0.06 \\
$20-24$ & 1.01 & 0.97 & -0.04 & & 0.87 & 0.99 & +0.12 \\
$25-29$ & 2.36 & 2.30 & -0.06 & & 2.35 & 2.41 & +0.06 \\
$30-34$ & 3.62 & 3.52 & -0.10 & & 4.07 & 3.82 & -0.25 \\
$35-39$ & 4.54 & 4.57 & +0.03 & & 5.27 & 5.08 & -0.19 \\
$40-44$ & 5.23 & 5.27 & +0.04 & & 5.78 & 5.92 & +0.14 \\
$45-49$ & 5.39 & 5.36 & -0.03 & & 5.89 & 6.12 & +0.23 \\
\hline
\end{tabular}

SOURCE: Thailand, Office of Prime Minister (1962, 1973).

corded in the two censuses. In 1960 respondents were asked to state their age directly, whereas in 1970 age was derived from the reported date of birth. Because many Thais state age at next, rather than last, birthday, Chamratrithirong (1976) has calculated that Thai women are at least one-half year younger, on the average, than the age given in the 1960 census. Thus women in the stated age group 20-24 in 1960 were actually at least one-half year younger than women in the same age group in the 1970 census. Because, within the younger age groups, fertility is higher among women who are nearer the upper limit of the age group than among younger women, this overstatement of age means that fertility was understated for younger women in the 1960 census. If a correction were made for this factor, a greater decline in children ever born would be evident. Even allowing for this factor, however, the data on children ever born appear to indicate a smaller fertility decline than the birth registration data. It is also possible that the absence of much change in the data on children ever born for Chiang Mai Province between 1960 and 1970 is due to a relative understatement of the fertility levels in the 1960 census. If this were true, then the estimates of completeness of birth registration derived by the Brass technique and presented in Table 4 would be overstated. The important point for the present analysis is that even if underregistration has been greater than assumed, the unadjusted registration results can be examined for evidence of fertility decline as long as the completeness of registration did not deteriorate after 1960. Indeed, if registration were improving, the actual decline would be even greater than that indicated by the registered figures. 


\section{Total fertility rates}

Table 7, which presents unadjusted and adjusted total fertility rates for Chiang Mai Province for 1960 through 1975 based on registered births, shows a very substantial decline in fertility over the period covered, although the pace of decline was not uniform. Total fertility calculated from all births declined quite slowly up to 1964, much more precipitously during the remainder of the decade, and then again more

TABLE 7 Total fertility rates based on all registered births and births to residents only: Chiang Mai Province, 1960-75

\begin{tabular}{llll}
\hline & $\begin{array}{l}\text { Total fertility } \\
\text { based on all } \\
\text { registered births }\end{array}$ & $\begin{array}{l}\text { Percentage of births } \\
\text { to residents of } \\
\text { other provinces }\end{array}$ & $\begin{array}{l}\text { Adjusted total fertility } \\
\text { based on births to } \\
\text { residents only }\end{array}$ \\
\hline 1960 & 5.20 & 0.22 & 5.19 \\
1961 & 5.01 & 0.43 & 4.99 \\
1962 & 5.00 & 0.69 & 4.97 \\
1963 & 4.95 & 0.69 & 4.95 \\
1964 & 4.94 & 0.81 & 4.90 \\
1965 & 4.53 & 0.98 & 4.49 \\
1966 & 4.34 & 1.19 & 4.29 \\
1967 & 3.92 & 1.56 & 3.86 \\
1968 & 3.68 & 2.11 & 3.60 \\
1969 & 3.39 & 1.98 & 3.32 \\
1970 & 3.16 & 2.88 & 3.07 \\
1971 & 3.07 & 2.77 & 2.98 \\
1972 & 3.17 & 3.54 & 3.08 \\
1973 & 2.97 & 4.67 & 2.83 \\
1974 & 2.89 & $(5.69)^{\mathrm{c}}$ & 2.72 \\
1975 & 2.86 & 6.71 & 2.67 \\
\hline
\end{tabular}

NOTE: The base population figures in the calculation of the total fertility rate were derived through linear interpolation in each age group between the 1960 and 1970 census results and through linear extrapolation after 1970.

a Based on the ratio of the number of births in Chiang Mai City to residents of other provinces (mainly Lamphun) to the total number of births in Chiang Mai Province.

b Based on births to residents only. These are derived by reducing the registered total fertility rates by the percentage of births to nonresidents and assuming that no Chiang Mai women gave birth outside the province.

c Average of results for 1973 and 1975 because data were not available for 1974 .

SOURCES: Chiang Mai Province, Office of Health (undated); Thailand, Office of Prime Minister $(1962,1973)$; Thailand, Ministry of Public Health (1972c); Chiang Mai Province, Chiang Mai Municipal Office (undated). 
slowly between 1970 and 1975 . During the entire period, the total fertility rate declined by 45 percent.

The registered total fertility rate underestimates the decline of fertility among women resident in Chiang Mai Province because there was a steady increase in the proportion of deliveries in Chiang Mai City to women who were residents of other provinces during the 1960-75 period. Since births are registered by place of occurrence in Thailand, these births were credited to Chiang Mai Province. Although increasing numbers of women, especially from nearby Lamphun Province, were taking advantage of the extensive medical facilities in Chiang Mai City, it is unlikely that many residents of Chiang Mai Province went to other provinces to deliver. Adjusted figures based on births to Chiang Mai residents only indicate a somewhat greater decline in fertility rates, especially since 1970, than the unadjusted figures. For example, the unadjusted figures indicate a 9.5 percent decline in total fertility between 1970 and 1975, whereas the adjusted figures indicate a 13 percent decline. The overall decline during the 1960-75 period is 49 percent, as indicated by the adjusted figures. Both adjusted and unadjusted total fertility rates indicate a remarkable change in reproductive behavior within a very short period. The pace of fertility decline in Chiang Mai is probably unprecedented in the historical experience of the West.

\section{EVIDENCE BASED ON CENSUSES}

The population censuses of 1960 and 1970 provide data on the age structure of the population. As we have already observed, however, there is a problem in directly comparing the age distributions of 1960 and 1970 because age was obtained by the two censuses in different ways-from age in years in 1960 and from date of birth in 1970. This discrepancy explains why the proportion of the population under exact age 10 that was at age 0 was considerably higher for the Kingdom as a whole in 1970 than in 1960 (Table 8). In 1960 a number of infants under exact age 1 were reported as being age 1 because the respondents rounded the children's ages upward to one year. Obviously, this practice was not compensated for by people in younger ages being rounded up to age 0 since there were no younger ages. In other age groups, the distortion created by this response pattern was not very great because losses were offset by gains. In 1970 this problem did not occur because age at last birthday was calculated directly from date of birth (Chamratrithirong, 1976).

The procedure of analysis was, first, to calculate the percentage of 
TABLE 8 Percentage of children under age 10 in each single age in 1960 and 1970: Thailand, Chiang Mai, and three adjacent provinces

\begin{tabular}{|c|c|c|c|c|c|c|c|c|c|c|}
\hline \multirow[b]{2}{*}{ Age } & \multicolumn{5}{|l|}{1960} & \multicolumn{5}{|l|}{1970} \\
\hline & Thailand & $\begin{array}{l}\text { Chiang } \\
\text { Mai }\end{array}$ & $\begin{array}{l}\text { Lam- } \\
\text { phun }\end{array}$ & $\begin{array}{l}\text { Lam- } \\
\text { pang }\end{array}$ & $\begin{array}{l}\text { Chiang } \\
\text { Rai }\end{array}$ & Thailand & $\begin{array}{l}\text { Chiang } \\
\text { Mai }\end{array}$ & $\begin{array}{l}\text { Lam- } \\
\text { phun }\end{array}$ & $\begin{array}{l}\text { Lam- } \\
\text { pang }\end{array}$ & $\begin{array}{l}\text { Chiang } \\
\text { Rai }\end{array}$ \\
\hline 0 & 7.42 & 8.63 & 7.05 & 8.18 & 8.73 & 11.11 & 8.49 & 8.03 & 10.06 & 9.97 \\
\hline 1 & 10.84 & 10.73 & 10.91 & 10.97 & 11.41 & 10.13 & 8.21 & 8.43 & 9.08 & 9.20 \\
\hline 2 & 10.70 & 11.57 & 11.75 & 11.64 & 11.33 & 10.08 & 9.03 & 9.07 & 9.61 & 9.88 \\
\hline 3 & 11.19 & 11.57 & 11.42 & 11.10 & 11.71 & 10.24 & 9.71 & 9.80 & 9.76 & 10.01 \\
\hline 4 & 11.36 & 11.15 & 11.37 & 11.14 & 10.84 & 10.16 & 10.19 & 10.44 & 10.44 & 10.24 \\
\hline 5 & 10.58 & 10.66 & 10.84 & 10.72 & 10.46 & 10.44 & 10.08 & 10.53 & 10.44 & 10.33 \\
\hline 6 & 10.27 & 9.88 & 9.99 & 9.95 & 10.00 & 9.75 & 10.98 & 1.1 .10 & 10.60 & 10.29 \\
\hline 7 & 10.00 & 9.93 & 10.14 & 9.51 & 9.35 & 9.78 & 11.23 & 11.25 & 10.03 & 10.62 \\
\hline 8 & 9.30 & 8.57 & 8.70 & 8.85 & 8.96 & 9.50 & 11.37 & 10.86 & 10.26 & 10.18 \\
\hline 9 & 8.38 & 7.32 & 7.84 & 7.94 & 7.21 & 8.83 & 10.70 & 10.50 & 9.71 & 9.30 \\
\hline All ages & 100.00 & 100.00 & 100.00 & 100.00 & 100.00 & 100.00 & 100.00 & 100.00 & 100.00 & 100.00 \\
\hline
\end{tabular}

SOU RCE: Thailand, Office of Prime Minister $(1962,1973)$. 
the population for each age from 0 to 9 in 1960 and 1970 for Thailand, Chiang Mai, and the three adjacent provinces, as shown in Table 8. Then, the ratio of the proportion (from step 1) in each province to the proportion, in the same age and the same year, for Thailand as a whole was calculated (Table 9). The purpose of the second step was to standardize for differences in the way ages were derived in the two censuses. It is assumed that the distortions in the age data operated in the same direction for the provinces and the Kingdom as a whole for the particular censuses.

If the trends in fertility during the ten years prior to a census were similar for the four northern provinces and the Kingdom, we would expect the age distributions among children 0-9 to be approximately the same. Hence the ratios of the proportions in each age group for the four provinces to Thailand as a whole should be approximately 1.00 at each single year of age with no distinct patterns by age. This was roughly the case in the 1960 census. In contrast, if fertility were declining more rapidly in the provinces than in Thailand as a whole, the ratios should show a steady rise by age. This rise would indicate more rapidly declining birth rates in the provinces than in the whole Kingdom. Chiang Mai and Lamphun in 1970 show this pattern clearly,

TABLE 9 Ratio of proportions of children under age 10 in each single age for Chiang Mai and three adjacent provinces to the proportions for Thailand in 1960 and 1970

\begin{tabular}{|c|c|c|c|c|c|c|c|c|}
\hline \multirow[b]{2}{*}{ Age } & \multicolumn{4}{|l|}{1960} & \multicolumn{4}{|l|}{1970} \\
\hline & $\begin{array}{l}\text { Chiang } \\
\text { Mai } \\
\end{array}$ & $\begin{array}{l}\text { Lam- } \\
\text { phun }\end{array}$ & $\begin{array}{l}\text { Lam- } \\
\text { pang }\end{array}$ & $\begin{array}{l}\text { Chiang } \\
\text { Rai } \\
\end{array}$ & $\begin{array}{l}\text { Chiang } \\
\text { Mai } \\
\end{array}$ & $\begin{array}{l}\text { Lam- } \\
\text { phun }\end{array}$ & $\begin{array}{l}\text { Lam- } \\
\text { pang }\end{array}$ & $\begin{array}{l}\text { Chians } \\
\text { Rai } \\
\end{array}$ \\
\hline 0 & 1.16 & 0.95 & 1.10 & 1.18 & 0.76 & 0.72 & 0.91 & 0.90 \\
\hline 1 & 0.99 & 1.01 & 1.01 & 1.05 & 0.81 & 0.83 & 0.90 & 0.91 \\
\hline 2 & 1.08 & 1.10 & 1.09 & 1.06 & 0.90 & 0.90 & 0.95 & 0.98 \\
\hline 3 & 1.03 & 1.02 & 0.99 & 1.05 & 0.95 & 0.96 & 0.95 & 0.98 \\
\hline 4 & 0.98 & 1.00 & 0.98 & 0.95 & 1.00 & 1.03 & 1.03 & 1.01 \\
\hline 5 & 1.01 & 1.02 & 1.01 & 0.99 & 0.97 & 1.01 & 1.00 & 0.99 \\
\hline 6 & 0.96 & 0.97 & 0.97 & 0.97 & 1.13 & 1.13 & 1.09 & 1.06 \\
\hline 7 & 0.99 & 1.01 & 0.95 & 0.94 & 1.15 & 1.15 & 1.03 & 1.09 \\
\hline 8 & 0.92 & 0.94 & 0.95 & 0.96 & 1.20 & 1.14 & 1.08 & 1.07 \\
\hline 9 & 0.87 & 0.94 & 0.95 & 0.86 & 1.21 & 1.19 & 1.10 & 1.05 \\
\hline
\end{tabular}


while the other two provinces do so to a lesser extent. The evidence from age distributions of children 0-9 in the 1970 census is generally consistent with the data from birth registration in indicating a rapid fertility decline in Chiang Mai and Lamphun Provinces between 1960 and 1970.

\section{EVIDENCE BASED ON SCHOOL DATA}

For Chiang Mai Province we have data on the number of children entering the first grade of primary school. These data are not equivalent to the registered births approximately seven years earlier but are dependent on the number of live births as affected by infant and childhood mortality. Thai children are required by law to begin school when they are seven years old and must complete four years of schooling. School attendance in Thailand has improved with time. For example, in Chiang Mai in 1974, the number of children entering the first grade was 99.4 percent of all seven-year-olds (Chiang Mai Province, Provincial Education Section, 1974a). If there has been any distortion in the enrollment figures over time it would be to show increasing numbers of children prior to 1974 because of increasing completeness of enrollment. The only other problem that could be associated with estimating the fertility trend from school enrollment data would be increasing enrollments in private schools, which are not included in the enrollment data used in this analysis.

Enrollment data from 890 primary schools, excluding approximately 40 private schools, were analyzed. Table 10 shows the number of live births registered between 1955 and 1967 and the corresponding number of seven-year-olds in Chiang Mai Province registered in the first grade between 1962 and 1974. The ratio of number of pupils registered in first grade to number of live births registered seven years earlier fluctuated between .86 and .92 ; only in 1964 did this ratio drop to .83 . The number of live births increased substantially beginning in 1955, reached a peak in 1959 , and declined substantially thereafter. The number of seven-year-olds registered for the first grade showed the same trend as number of live births registered since 1955; the number of children registered in 1974 (who were born in 1967) was less than that of children registered in 1962 (born in 1955) in spite of a general population increase. This decrease would not have occurred if the fertility level had not declined, unless there had been considerable outmigration of school children from the province or increasing enrollments in private schools. These possibilities need further investigation. 
TABLE 10 Percentage of children born between 1955 and 1967 who were registered in the first grade of 890 primary schools between 1962 and 1974: Chiang Mai Province

\begin{tabular}{llll}
\hline $\begin{array}{l}\text { Year of } \\
\text { birth }\end{array}$ & $\begin{array}{l}\text { Number of } \\
\text { registered } \\
\text { live births }\end{array}$ & $\begin{array}{l}\text { Number of children } \\
\text { registered in first grade } \\
\text { seven years later }\end{array}$ & $\begin{array}{l}\text { Percentage of live-born } \\
\text { children registered } \\
\text { seven years later }\end{array}$ \\
\hline 1955 & 25,267 & 22,930 & 90.8 \\
1956 & 28,296 & 24,412 & 86.3 \\
1957 & 28,920 & 25,703 & 88.9 \\
1958 & 29,112 & 26,820 & 92.1 \\
1959 & 31,228 & 27,526 & 88.1 \\
1960 & 30,234 & 27,071 & 89.5 \\
1961 & 29,543 & 26,969 & 91.3 \\
1962 & 29,840 & 26,297 & 88.1 \\
1963 & 29,878 & 25,784 & 86.6 \\
1964 & 30,075 & 25,004 & 83.1 \\
1965 & 28,030 & 24,647 & 87.9 \\
1966 & 27,295 & 23,920 & 88.0 \\
1967 & 24,022 & 21,145 & \\
\hline
\end{tabular}

SOU RCES: Chiang Mai Province, Office of Health (undated); Chiang Mai Province, Provincial Education Section (1974b).

\section{AREAL DIFFERENTIALS IN THE CHIANG MAI FERTILITY DECLINE}

Because of Thailand's geography, people in the Northern Region have unequal access to health services, family planning, and education. There are also inequalities in the extent of modernization. All of these factors might affect fertility.

Fertility trends were examined by place of residence within Chiang Mai Province. The analysis was based on two sources of data, the number of registered live births during 1956-75 and a 1974 provincial school survey. (Comparable data for the three adjacent provinces were not available.)

For the purposes of this analysis, the 18 amphoes (districts) in Chiang Mai Province were classified into five areas as shown in Figure 4 and described below:

Area A is the Chiang Mai City area, which in 1970 contained 137,395 people. Its population has good access to governmental and nongovernmental services. 
FIGURE 4 Chiang Mai Province divided into five study areas by relative accessibility to Chiang Mai City

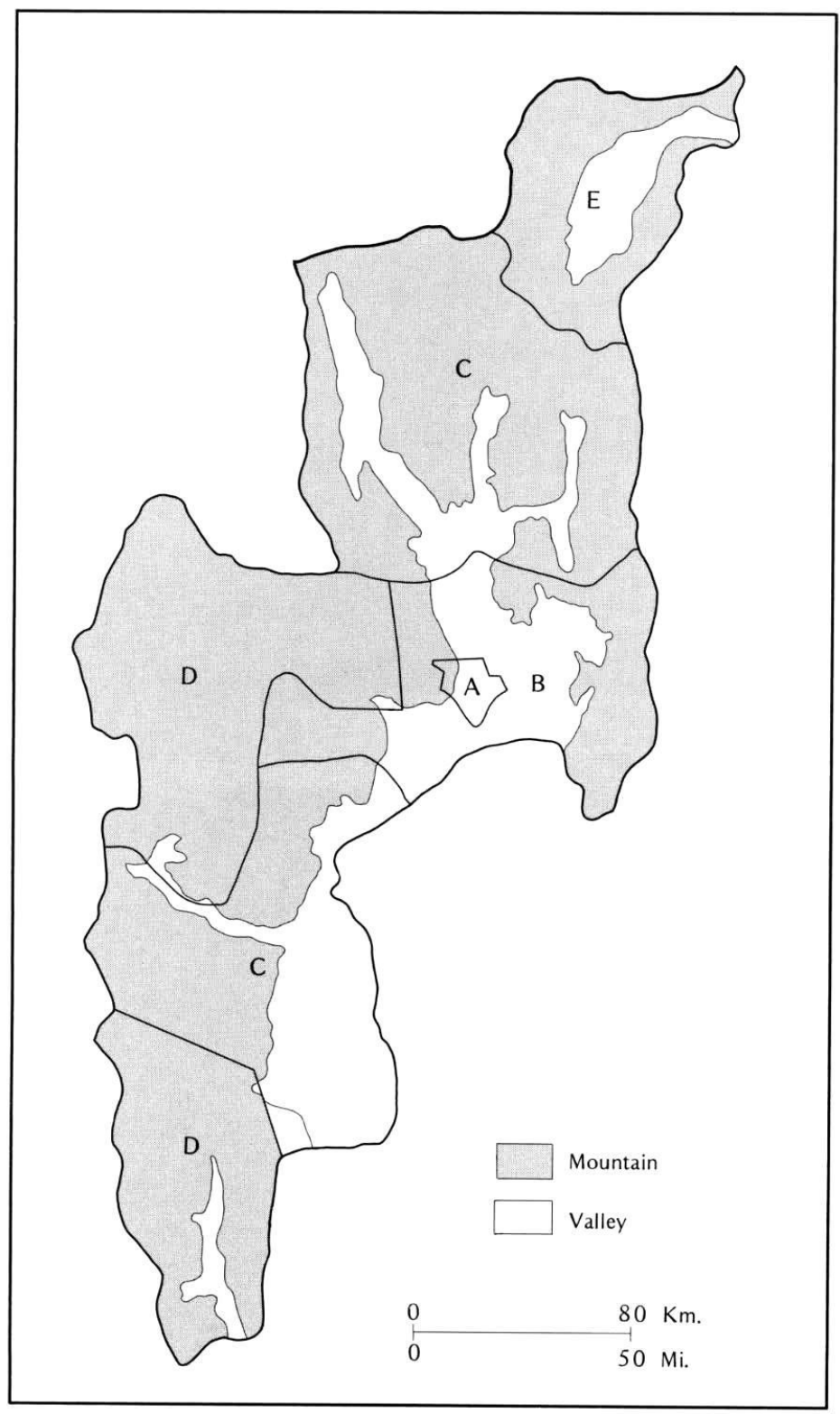


Area B, comprising the seven urban peripheral amphoes surrounding Chiang Mai City, contained 432,078 people in 1970. Transportation by small buses from these amphoes to Chiang Mai City is convenient during all seasons.

Area C, in two parts, consists of five rural amphoes whose combined population was 252,203 in 1970 . The majority of the population is concentrated in valleys. Transportation to Chiang Mai City is possible during all seasons.

Area D, also in two parts, comprises three rural amphoes with a population of 71,217 that is widely dispersed in mountainous areas. Transportation to Chiang Mai City is possible only in the summer season, and even then entails some difficulty.

Area E consists of two rural amphoes. Their 133,557 inhabitants live in an isolated wide valley and have few opportunities to obtain services from Chiang Mai City.

\section{Evidence based on areal birth registration data}

At the Chiang Mai Provincial Health Center, record keeping is excellent. There are almost complete records of live births registered in each month during the period 1956-75 by birth order and age of mother for all 18 amphoes. These data cannot be used directly, however, because births to all mothers who had deliveries at hospitals in the Chiang Mai municipal area were registered at the Chiang Mai municipal office, regardless of the area of residence of the mother. As we have already noted, this practice inflates the number of births registered in the municipal area. In 1975, for example, 9,801 live births were registered in the Chiang Mai municipal area, but only 2,504 of them were to mothers actually residing in Chiang Mai City. The birth records of 83,298 live births registered in the municipal area between 1956 and 1975 were therefore analyzed to determine the amphoe of residence and age of mother.

In the five study areas of Chiang Mai Province, the numbers of live births registered between 1956 and 1975 have been declining markedly except in study area D (Table 11). In area B, where the largest decline took place, the number of live births in 1975 was 7,283; this is equivalent to half of the live births registered in 1959.

Table 12 shows the median age of women at the time of childbirth in the five study areas over the period 1956-75. The median age in study area A increased from 26.6 in 1956 to 28.4 in 1964 and thereafter declined. It was 24.6 years in 1971 and remained consistently at 24.6 until 1975 . The median age at childbirth in study area B was 
TABLE 11 Live births registered in the five study areas of Chiang Mai Province: $1956-75$

\begin{tabular}{lrrrrr}
\hline & \multicolumn{5}{l}{ Study area $^{\mathrm{a}}$} \\
\cline { 2 - 6 } Year $^{\mathrm{b}}$ & $\mathrm{A}$ & $\mathrm{B}$ & $\mathrm{C}$ & $\mathrm{D}$ & $\mathrm{E}$ \\
\hline 1956 & 3,474 & 14,018 & 7,152 & 702 & 2,831 \\
1957 & 3,533 & 13,823 & 7,371 & 819 & 3,366 \\
1958 & 3,790 & 13,794 & 7,078 & 1,045 & 3,236 \\
1959 & 3,791 & 14,779 & 7,702 & 1,007 & 3,898 \\
1960 & 3,711 & 14,744 & 7,126 & 1,101 & 3,691 \\
1961 & 3,426 & 14,118 & 7,083 & 1,137 & 3,659 \\
1962 & 3,403 & 14,339 & 7,176 & 1,082 & 3,635 \\
1963 & 3,415 & 13,846 & 7,420 & 1,167 & 3,818 \\
1964 & 3,304 & 13,432 & 7,787 & 1,207 & 4,118 \\
1965 & 3,185 & 12,648 & 6,956 & 1,192 & 3,751 \\
1966 & 2,979 & 11,847 & 6,889 & 1,231 & 3,881 \\
1967 & 3,175 & 10,392 & 6,332 & 1,111 & 3,604 \\
1968 & 2,844 & 9,517 & 5,887 & 1,280 & 3,809 \\
1969 & 2,952 & 8,685 & 5,679 & 1,122 & 3,348 \\
1970 & 2,893 & 7,928 & 5,332 & 1,198 & 3,278 \\
1971 & 2,980 & 7,718 & 5,545 & 1,105 & 3,048 \\
1972 & 2,871 & 7,795 & 6,167 & 1,321 & 3,113 \\
1973 & 2,852 & 7,518 & 5,450 & 1,221 & 2,548 \\
1974 & u & u & u & u & u \\
1975 & 2,720 & 7,283 & 5,073 & 1,294 & 2,337 \\
1975 births as a per- & & & & & \\
centage of 1960 births & 73.3 & 49.4 & 71.2 & 117.5 & 63.3 \\
\hline
\end{tabular}

u-unavailable because birth registration data for 1974 were incomplete.

a For definition of areas, see Figure 4.

b Yearly totals of registered births in areas $A-E$ do not exactly equal yearly totals shown in Table 10 because the data came from different sources.

SOURCES: Chiang Mai Province, Office of Health (undated); Chiang Mai Province, Chiang Mai Municipal Office (undated).

slightly higher than in area A between 1956 and 1971, and slightly lower thereafter. But the trend was similar in the two areas, median age increasing between 1956 and 1964, and declining thereafter. The median ages of women at childbirth in study areas $\mathrm{C}$ and $\mathrm{E}$ show the same pattern as in areas $\mathrm{A}$ and $\mathrm{B}$, but the pattern in area $\mathrm{D}$ is different. In $\mathrm{D}$, the median age of mothers increased from 27.0 to 28.4 years be- 
TABLE 12 Median age of mothers at childbirth for five study areas of Chiang Mai Province: 1956-75

\begin{tabular}{|c|c|c|c|c|c|}
\hline \multirow[b]{2}{*}{ Year } & \multicolumn{5}{|c|}{$\underline{\text { Study area }}{ }^{\mathrm{a}}$} \\
\hline & A & B & C & D & $E$ \\
\hline 1956 & 26.6 & 27.2 & 26.8 & 27.0 & 26.2 \\
\hline 1957 & 26.8 & 27.5 & 27.1 & 27.5 & 26.6 \\
\hline 1958 & 27.2 & 27.9 & 27.1 & 27.5 & 26.9 \\
\hline 1959 & 27.4 & 28.1 & 27.5 & 27.9 & 26.9 \\
\hline 1960 & 27.5 & 28.4 & 27.4 & 27.9 & 27.4 \\
\hline 1961 & 27.8 & 28.6 & 27.6 & 27.9 & 27.3 \\
\hline 1962 & 28.1 & 29.0 & 27.8 & 27.7 & 27.6 \\
\hline 1963 & 28.2 & 29.2 & 27.8 & 28.0 & 28.0 \\
\hline 1964 & 28.4 & 29.7 & 28.1 & 28.0 & 28.3 \\
\hline 1965 & 28.2 & 29.5 & 27.9 & 28.3 & 27.8 \\
\hline 1966 & 27.9 & 29.2 & 27.9 & 28.4 & 27.8 \\
\hline 1967 & 27.3 & 28.9 & 27.3 & 28.4 & 27.3 \\
\hline 1968 & 27.0 & 28.2 & 27.1 & 28.4 & 27.1 \\
\hline 1969 & 26.2 & 27.2 & 26.1 & 27.7 & 26.4 \\
\hline 1970 & 25.6 & 25.9 & 24.9 & 26.9 & 25.8 \\
\hline 1971 & 24.6 & 24.9 & 24.7 & 26.7 & 25.2 \\
\hline 1972 & 24.6 & 24.1 & 24.2 & 26.4 & 24.6 \\
\hline 1973 & 24.6 & 23.8 & 24.3 & 26.0 & 24.0 \\
\hline 1974 & $\mathrm{u}$ & $\mathrm{u}$ & $\mathrm{u}$ & $\mathrm{u}$ & $\mathrm{u}$ \\
\hline 1975 & 24.6 & 23.4 & 23.2 & 25.1 & 23.4 \\
\hline
\end{tabular}

u-unavailable because birth registration data for 1974 were incomplete.

a For definition of areas, see Figure 4.

SOURCES: Chiang Mai Province, Office of Health (undated); Chiang Mai Province, Chiang Mai Municipal Office (undated).

tween 1956 and 1966; it remained at 28.4 for three years, then began a definite but slow decline in 1969 . The decline in median age occurred later in area D (starting in 1968 instead of 1964) and was less marked than in the other areas.

The declining median age of maternity could reflect either a reduction in higher order births to older women or a decline in the age at marriage. Since there is no evidence for the latter, it suggests that fertility at older ages has decreased in all areas, but least in area D.

\section{Evidence based on areal school data}

A school survey was conducted by the Chiang Mai Provincial Educa- 
tion section in 1974. Each of the 878 government schools in Chiang Mai Province, with the exception of 12 municipal schools, was included in the survey. Information collected included number of children by age and grade in 1973 and 1974, number of children in each grade from 1966 to 1974 , and number of children who failed examinations between 1968 and 1973. This survey also included valuable demographic data-specifically, the number of children aged seven years and registered in the first grade from 1962 through 1974. In addition to this survey, a survey of the 12 municipal schools and 40 private schools was conducted to obtain similar data. The survey of the private schools, however, had to be abandoned for two reasons. First, there is no minimum age requirement for pupils entering the first grade of private schools, and this complicates the effort to determine the number of seven-year-olds in each year. Second, some of the private schools were not willing to share their original data. Therefore, the data cover only the 890 public schools.

Table 13 shows the number of seven-year-old pupils registered in the first grade of the 890 government schools between 1962 and 1974

\section{TABLE 13 Seven-year-old pupils (born between 1955 and 1967) registered in the first grade of 890 government schools between 1962 and 1974, by school year and survey study area: Chiang Mai Province}

\begin{tabular}{llllll}
\hline & \multicolumn{6}{l}{ Number of pupils, by study area } \\
\cline { 2 - 6 } School year & A & B & C & D & E \\
\hline 1962 & 2,000 & 11,563 & 5,444 & 683 & 3,240 \\
1963 & 2,157 & 12,419 & 6,067 & 737 & 3,032 \\
1964 & 2,293 & 12,645 & 6,320 & 945 & 3,500 \\
1965 & 2,166 & 13,257 & 6,699 & 944 & 3,754 \\
1966 & 2,168 & 13,935 & 6,543 & 1,011 & 3,869 \\
1967 & 2,249 & 13,613 & 6,527 & 1,053 & 3,629 \\
1968 & 2,170 & 12,806 & 6,864 & 1,033 & 4,096 \\
1969 & 2,144 & 12,650 & 6,409 & 1,143 & 3,951 \\
1970 & 2,124 & 11,980 & 6,665 & 1,182 & 3,833 \\
1971 & 2,013 & 11,573 & 6,518 & 1,189 & 3,711 \\
1972 & 2,086 & 10,924 & 6,593 & 1,185 & 3,859 \\
1973 & 1,901 & 10,401 & 6,778 & 1,269 & 3,571 \\
1974 & 1,719 & 8,640 & 6,019 & 1,182 & 3,585 \\
\hline
\end{tabular}

a For definition of study areas, see Figure 4.

SOU RCE: Chiang Mai Province, Provincial Education Section (1974b). 
by school year and survey area. The data suggest a pattern consistent with that of registered live births: generally, the number of pupils increased in the early 1960s and declined beginning in the late 1960s in study areas $\mathrm{A}, \mathrm{B}, \mathrm{C}$, and $\mathrm{E}$. The decrease in enrollment is most marked during the 1970s and is consistent with a fertility decline during the 1960s. In contrast, the number of pupils in area D does not show any decline throughout the period of study.

The data in Tables 11 and 13 refer to the same individuals; children born in 1956, for example, would be in school seven years later in 1963. Provided the impact of migration is negligible, the ratio of the number of pupils (Table 13) to the number of live births registered seven years before in the same area (Table 11) should be slightly less than 1 owing to infant and child mortality, which would reduce the number who eventually reach school age.

Table 14 shows that the lowest ratios of seven-year-old pupils to live births seven years before occurred in study area A throughout the period of 1956-67. This does not mean that Chiang Mai City (area A) experienced a higher level of infant or child mortality than the other

TABLE 14 Ratio of seven-year-olds registered in first grade to number of live births seven years earlier in the five study areas of Chiang Mai Province: 1956-67

\begin{tabular}{llllll}
\hline \multirow{2}{*}{ Year of birth } & \multicolumn{5}{l}{ Study area } \\
\cline { 2 - 6 } & $\mathrm{A}$ & $\mathrm{B}$ & $\mathrm{C}$ & $\mathrm{D}$ & $\mathrm{E}$ \\
\hline 1956 & 0.62 & 0.89 & 0.85 & 1.05 & 1.07 \\
1957 & 0.65 & 0.92 & 0.86 & 1.15 & 1.04 \\
1958 & 0.57 & 0.96 & 0.95 & 0.90 & 1.16 \\
1959 & 0.57 & 0.94 & 0.85 & 1.00 & 0.99 \\
1960 & 0.61 & 0.92 & 0.92 & 0.96 & 0.98 \\
1961 & 0.63 & 0.91 & 0.97 & 0.91 & 1.12 \\
1962 & 0.63 & 0.88 & 0.89 & 1.06 & 1.09 \\
1963 & 0.62 & 0.87 & 0.90 & 1.01 & 1.00 \\
1964 & 0.61 & 0.86 & 0.84 & 0.99 & 0.90 \\
1965 & 0.66 & 0.86 & 0.95 & 0.99 & 1.03 \\
1966 & 0.64 & 0.88 & 0.98 & 1.03 & 0.92 \\
1967 & 0.54 & 0.83 & 0.95 & 1.06 & 1.00 \\
\hline
\end{tabular}

a For definition of study areas, see Figure 4.

SOU RCES: Chiang Mai Province, Office of Health (undated); Chiang Mai Province, Provincial Education Section (1974b); Chiang Mai Province, Chiang Mai Municipal Office (undated). 
areas, but rather that more children in this area attend private schools. (As noted above, there are approximately 40 private schools in Chiang Mai City.)

The ratios in study areas $\mathrm{B}$ and $\mathrm{C}$ seem to be reasonable. The ratios in area $B$ tend to be lower than in area $C$ since 1961 because some wellto-do people in area B send their children to private schools in Chiang Mai City; this practice has been increasing in recent years.

An unexpected phenomenon, ratios of unity or more, is observed in study areas D and E. There is no pattern of increase or decline, and fluctuations are erratic. It is unlikely that in these two relatively inaccessible regions there was unusually low infant or child mortality. A more probable explanation is that there was birth underregistration in both areas between 1956 and 1967, and possibly increasing proportions of children enrolling in schools as well. Compared with these two study areas, birth underregistration in Chiang Mai Province overall is lower-and very likely lower than in Thailand as a whole.

\section{DISCUSSION}

When birth registration data that are known to be incomplete are the only source of annual fertility trends, it is necessary to compare them with data from other sources. In this study, birth registration data were supplemented by the population censuses of 1960 and 1970, and by school registration data. Following are some general comments about the quality of the data used for the analysis, related findings, and the relationship of fertility decline to several intermediate variables.

\section{Quality of the birth registration data}

Concern has often been expressed by demographers over the completeness of birth registration data. Two studies, using different approaches, have found evidence of birth underregistration in Thailand, though their estimates of underregistration vary between 15 and 33 percent. The first, a Survey of Population Change (Thailand, Office of Prime Minister, 1970), was conducted during 1964-67 to estimate both the extent of incompleteness in the vital registration system and the general levels of fertility and mortality. According to this survey, 84.2 percent of male and 84.6 percent of female live births were registered. The second study, by Rungpitarangsi (1974), applied the Brass technique $(\mathrm{P} / \mathrm{F}$ ratio) for estimating fertility from birth registration data and census data. Rungpitarangsi found lower rates of birth coverage67.3 percent and 71.5 percent in 1960 and 1970, respectively. 
There are many reasons to believe that underregistration in Chiang Mai Province might be less than that suggested by the two earlier studies on Thailand as a whole. As was shown in Figure 2, birth registration in Chiang Mai Province seems to have improved ten years before that of the Kingdom as a whole. It is highly unlikely that birth registration deteriorated during the late 1960s and early 1970s. Application of the Brass technique $(\mathrm{P} / \mathrm{F}$ ratio) to birth registration data from Chiang Mai Province in 1960 indicated that only 1.2 percent of births were unregistered. Moreover, the analysis presented above indicates that four areas of Chiang Mai Province (including Chiang Mai City), with a total of 93 percent of the provincial population, started fertility declines at the same time in 1964; this was before the decline of fertility in study area $\mathrm{D}$, where the majority of the population lives in isolated, mountainous settlements. This pattern of decline seems plausible. If it were due purely to a deterioration in registration, it would mean that registration became worse in Chiang Mai City first and then subsequently in the mountainous areas. That explanation seems unlikely. Further evidence based on school registration data suggests that some birth underregistration occurred in study areas D and $\mathrm{E}$ but that registration has not deteriorated. These two areas comprise only 19.9 percent of the Chiang Mai Province population. Finally, when birth registration data in Chiang Mai Province were compared with the population censuses of 1960 and 1970 and with the school registration data for the period 1962-74, they were found to be consistent.

\section{Related findings}

Other studies of fertility trends in Thailand since 1960 tend to support the findings presented here. Of particular interest are the National Longitudinal Study of Social, Economic, and Demographic Change conducted by Chulalongkorn University, and the Survey of Population Change conducted by the National Statistical Office. Results from the first rural round of the Longitudinal Study conducted in April and May of 1969 and reported by Knodel and Prachuabmoh (1974) indicate that rural women had an average of more than six live births by the time they reached the end of their childbearing years. Results from the second round of the survey conducted three years later indicate a substantial decline in marital fertility for the whole of Thailand (Knodel and Pitaktepsombati, 1975). The present analysis of the proportion of all births that are of third or higher order has suggested that the national fertility decline now under way may have started in the 
mid-1960s. The same evidence combined with more direct fertility measures indicates that the rapid fertility decline in Chiang Mai Province probably began in the early 1960s.

The Survey of Population Change for 1964-65 and 1974-75 (Thailand, Office of Prime Minister, 1977) revealed fertility differentials among regions in both periods, as well as changes over time. In 196465 the Northeastern Region had the highest total fertility, followed by the Northern Region, whereas total fertility was lowest in the Central Region (Table 15). In 1974-75, the Northeastern Region still had the highest fertility but the Northern Region was lowest instead of the Central Region. It is noteworthy that total fertility in the Northern Region in 1974-75 was only slightly higher than in Bangkok, the major metropolitan area of Thailand; the crude birth rate in the Northern Region was actually lower than in Bangkok. There was a dramatic decline in total fertility in the Northern Region over the ten-year period, from 6.5 in $1964-65$ to 3.8 in $1974-75$, or 41.5 percent. The present study supports these findings. According to the data analyzed above, fertility in Chiang Mai and Lamphun Provinces in the 1970s was much lower than the 1974-75 level in Bangkok.

This study shows that there were also great differences in fertility between provinces within the Northern Region of Thailand. Chiang Mai and Lamphun Provinces had rapid fertility declines after 1964 and Lampang Province had a decline after 1967, but there was no definite trend in Chiang Rai.

TABLE 15 Fertility differentials between 1964-65 and 1974-75: regions of Thailand

\begin{tabular}{lccllll}
\hline & \multicolumn{2}{c}{ Crude birth rate } & & \multicolumn{2}{c}{ Total fertility } \\
\cline { 2 - 3 } Region & $1964-65$ & $1974-75$ & & $1964-65$ & $1974-75$ \\
\hline Northern Region & 43.7 & 26.6 & & 6.5 & 3.8 \\
Bangkok & $\mathrm{u}$ & 32.6 & & $\mathrm{u}$ & 3.6 \\
Central (excluding Bangkok) & 39.7 & 34.1 & & 5.9 & 4.7 \\
Southern Region & 40.9 & 41.4 & & 6.0 & 6.3 \\
Northeastern Region & 43.5 & 45.0 & & 6.6 & 6.6 \\
$\quad$ Thailand & 42.2 & 37.0 & & 6.3 & 5.2 \\
\hline
\end{tabular}

u-unavailable.

SOURCE: Thailand, Office of Prime Minister (1977). 


\section{The fertility decline and intermediate variables}

The fertility decline in the Northern Region is so striking, especially in Chiang Mai and Lamphun Provinces where total fertility dropped almost 50 percent in 15 years, that some speculation about its causes is appropriate. The decline could be due to a later age at marriage, to the adoption of contraceptive techniques by large numbers of couples, or to less direct influences. Although research on causes of the decline is still in a preliminary stage, several hypotheses are suggested.

A decline in the proportion of ever married women in the younger reproductive ages would suggest increasing age at marriage. Table 16 reveals that such a decline occurred between 1960 and 1970 in Chiang Mai and Lamphun Provinces, but was minor. In 1970, the proportions of women who had married by age 29 were only about 2 percent lower than in 1960. This decrease in the proportion of ever married women is too small to have accounted for more than a minimal share of the fertility decline observed in the Chiang Mai and Lamphun Provinces since 1964.

With respect to family planning practice, in Chiang Mai family planning was first introduced in 1963 by Dr. E.B. McDaniel, a missionary physician at McCormick Hospital. Since that time additional programs have been initiated, including family planning clinics in towns outside Chiang Mai City and mobile family planning clinics serving the rural population. Furthermore, since 1967 the Thai government has distributed oral contraceptives through first and second class health centers and through auxiliary nurse midwife offices.

TABLE 16 Proportion of women ever married, by age group: Chiang Mai and Lamphun provinces, 1960 and 1970

\begin{tabular}{llllllll}
\hline & \multicolumn{2}{l}{ Chiang Mai } & \multicolumn{2}{l}{ Lamphun } \\
Age & 1960 & 1970 & $\begin{array}{l}\text { Net change } \\
1970-1960\end{array}$ & 1960 & 1970 & $\begin{array}{l}\text { Net change } \\
1970-1960\end{array}$ \\
\hline $15-19$ & 20.0 & 19.7 & -0.3 & 11.4 & 14.7 & +3.3 \\
$20-24$ & 71.1 & 65.8 & -5.3 & 63.1 & 61.7 & -1.4 \\
$25-29$ & 90.1 & 88.0 & -2.1 & 87.8 & 85.8 & -2.0 \\
$30-34$ & 94.9 & 94.7 & -0.2 & 93.0 & 93.5 & +0.5 \\
$35-39$ & 96.1 & 96.3 & +0.2 & 95.0 & 94.8 & -0.2 \\
$40-44$ & 97.0 & 96.8 & -0.2 & 95.7 & 95.3 & -0.4 \\
$45-49$ & 97.5 & 96.9 & -0.6 & 95.8 & 95.3 & -0.5 \\
\hline
\end{tabular}

SOURCE: Thailand, Office of Prime Minister $(1962,1973)$. 
The following observations relate both to the McCormick Family Planning Programme and data available from the government program (Thailand, Ministry of Public Health, 1969, 1970, 1971, 1972b, 1974, 1976). Sufficient supplies of contraceptives to meet the demands of the McCormick Family Planning Programme were not available until 1969. Thereafter, the number of acceptors increased every year, except in 1971 (Table 17). The majority of these clients accepted an injectable contraceptive, which was introduced in the program in 1965. Pardthaisong, McDaniel, and Gray (1975) found that the patients who used injectable contraceptives showed not only very low rates of method failure, but also high continuation rates-73, 56, and 46 percent after one, two, and three years, respectively. The proportion of new acceptors in the age group 20-29, with the highest level of fer-

TABLE 17 New acceptors and percentage of acceptors by province in the McCormick Family Planning Programme, 1963-75, and new acceptors in the government program, 1967-75

\begin{tabular}{|c|c|c|c|c|c|c|}
\hline \multirow[b]{3}{*}{ Year } & \multicolumn{5}{|c|}{ McCormick Family Planning Programme } & \multirow[b]{3}{*}{$\begin{array}{l}\text { New acceptor } \\
\text { in the govern- } \\
\text { ment program }\end{array}$} \\
\hline & \multirow[b]{2}{*}{$\begin{array}{l}\text { New } \\
\text { acceptors }\end{array}$} & \multicolumn{4}{|c|}{ Percentage of acceptors } & \\
\hline & & $\begin{array}{l}\text { Chiang } \\
\text { Mai }\end{array}$ & $\begin{array}{l}\text { Lam- } \\
\text { phun }\end{array}$ & $\begin{array}{l}\text { Other } \\
\text { program } \\
\text { areas }\end{array}$ & Total & \\
\hline 1963 & 157 & 76.4 & 19.7 & 3.8 & 100.0 & \multirow{7}{*}{$7,588^{\mathrm{a}}$} \\
\hline 1964 & 892 & 70.1 & 22.6 & 7.4 & 100.0 & \\
\hline 1965 & 785 & 67.4 & 26.2 & 6.6 & 100.0 & \\
\hline 1966 & 1,400 & 74.9 & 19.4 & 5.7 & 100.0 & \\
\hline 1967 & 4,446 & 70.4 & 26.6 & 3.0 & 100.0 & \\
\hline 1968 & 3,379 & 79.8 & 19.1 & 1.1 & 100.0 & \\
\hline 1969 & 6,203 & 70.5 & 27.4 & 2.0 & 100.0 & \\
\hline 1970 & 9,114 & 80.0 & 19.3 & 0.7 & 100.0 & 5,916 \\
\hline 1971 & 7,941 & 81.7 & 17.6 & 0.6 & 100.0 & 10,066 \\
\hline 1972 & 8,678 & 84.7 & 14.8 & 0.5 & 100.0 & 10,647 \\
\hline 1973 & 13,361 & 79.7 & 19.6 & 0.7 & 100.0 & 9,734 \\
\hline 1974 & 14,681 & 79.8 & 19.6 & 0.6 & 100.0 & 10,062 \\
\hline 1975 & 15,215 & 81.1 & 17.6 & 1.2 & 100.0 & 15,093 \\
\hline $1965-75$ & 86,252 & 79.3 & 19.5 & 1.2 & 100.0 & 69,106 \\
\hline
\end{tabular}

a Cumulative new acceptors 1967-69.

SOU RCES: New acceptors in McCormick Family Planning Programme from McCormick

Family Planning Programme records. New acceptors in the government program from

Thailand, Ministry of Public Health $(1969,1970,1971,1972 b)$. 
tility, substantially increased during the period under review-from 50.7 percent in 1970 to 67.4 percent in 1975 .

Most of the acceptors in the McCormick Programme were from Chiang Mai and Lamphun Provinces. Data on new acceptors help support the validity of the analysis of fertility trends in Chiang.Mai and Lamphun. "New acceptors" are defined as women who had never used any method from the McCormick Programme previously, who switched methods within the program, or who switched from the government program. The rates were calculated by dividing the number of new acceptors each year by the number of eligible women, defined as ever married women aged 15-44 who had not previously been new acceptors. The numbers of eligible women were estimated by linear interpolation between the 1960 and 1970 censuses and linear extrapolation for subsequent years. The estimated total number of ever married women aged 15-44 was then reduced each year by the cumulative number of new acceptors up to the previous year, after the cumulative number of new acceptors was first reduced by 3 percent to adjust for the proportion of previous new acceptors who reach age 45 each year and thus exceed the upper age limit set for eligible women.

New acceptor rates have risen rather steadily, as the results presented in Table 18 show. The total proportion of eligible women in Chiang Mai and Lamphun Provinces who accepted contraceptives through the McCormick Programme is quite substantial and lends further credence to the major fertility decline posited above. Within Chiang Mai Province, the very low acceptance rates for women in study area D clearly stand out as exceptions and are consistent with the exceptional fertility behavior for area $D$ revealed in the analysis presented earlier. Nevertheless, even these acceptance rates appear to have.increased in recent years, suggesting that in the near future women in area $D$ might join in the major fertility decline experienced elsewhere in the province.

In sum, it appears that with the exception of study area D, where the acceptability of contraceptives remained at a low level, acceptance of contraceptives by the populations of Chiang Mai and Lamphun Provinces between 1963 and 1975 was (1) substantial and increasing, and (2) diffused through the urban and rural areas from the beginning of the program in the 1960 s.

The contraceptive acceptance patterns in Chiang Mai and Lamphun, based on McCormick Hospital data, appear to be related to the findings of this study concerning fertility levels in the two provinces. First, the acceleration of the decline in the total fertility rate began roughly 
TABLE 18 New acceptors of McCormick Family Planning Programme as percentage of ever married women aged $15-44$, by year and study area

\begin{tabular}{|c|c|c|c|c|c|c|c|}
\hline \multirow[b]{2}{*}{ Year } & \multirow{2}{*}{$\begin{array}{l}\text { Chiang } \\
\text { Mai }\end{array}$} & \multirow[b]{2}{*}{ Lamphun } & \multicolumn{5}{|c|}{ Study area ${ }^{\mathrm{a}}$} \\
\hline & & & $\mathrm{A}$ & B & $\mathrm{C}$ & $\mathrm{D}$ & $\mathrm{E}$ \\
\hline 1963 & 0.09 & 0.08 & 0.41 & 0.06 & 0.01 & 0.00 & 0.03 \\
\hline 1964 & 0.46 & 0.52 & 1.29 & 0.53 & 0.16 & 0.02 & 0.11 \\
\hline 1965 & 0.38 & 0.53 & 0.43 & 0.55 & 0.30 & 0.05 & 0.13 \\
\hline 1966 & 0.75 & 0.70 & 0.55 & 1.23 & 0.39 & 0.02 & 0.50 \\
\hline 1967 & 2.23 & 3.01 & 2.40 & 3.82 & 0.96 & 0.02 & 0.39 \\
\hline 1968 & 1.93 & 1.67 & 2.28 & 3.33 & 0.66 & 0.03 & 0.56 \\
\hline 1969 & 3.13 & 4.39 & 3.42 & 5.15 & 1.73 & 0.07 & 1.04 \\
\hline 1970 & 5.31 & 4.65 & 4.92 & 7.49 & 4.02 & 0.12 & 4.74 \\
\hline 1971 & 4.90 & 3.82 & 5.50 & 6.72 & 3.27 & 0.14 & 4.82 \\
\hline 1972 & 5.71 & 3.55 & 6.40 & 7.33 & 3.71 & 0.26 & 7.50 \\
\hline 1973 & 8.56 & 7.35 & 6.46 & 11.29 & 7.28 & 0.42 & 11.25 \\
\hline 1974 & 10.00 & 8.53 & 6.96 & 13.35 & 9.76 & 0.48 & 11.82 \\
\hline 1975 & 11.33 & 8.42 & 8.61 & 15.23 & 10.55 & 0.68 & 14.22 \\
\hline \multirow{2}{*}{$\begin{array}{l}\text { Cumulative } \\
\text { acceptors in } \\
1975^{\mathrm{b}}\end{array}$} & & & & & & & \\
\hline & 39.27 & 34.32 & 34.16 & 50.34 & 33.20 & 2.11 & 41.68 \\
\hline
\end{tabular}

a For definition of study areas, see Figure 4.

b Cumulative acceptors have been adjusted for the women who accepted earlier but passed the reproductive age by 1975 (see text).

in 1964, coincident with the development of the McCormick Programme. Second, older women had a greater reduction in fertility than younger women, a finding that is consistent with data from the family planning program showing that the older women accepted family planning first, followed by the younger women. Third, the decline in fertility occurred almost at the same time in the urban and rural areas. Here again, family planning acceptors show a similar pattern. In study area $\mathrm{D}$ fertility declined slowly and minimally, and acceptance of family planning from the program was also less than in the other areas. Considering these findings, it seems reasonable to say that the rapid fertility decline in Chiang Mai and Lamphun Provinces was probably facilitated by the McCormick Family Planning Programme, which began to have large numbers of acceptors by the last half of the 1960s, and later by the government program. It does not seem justifiable, however, to attribute the entire fertility decline to these programs, since 
the evidence suggests that fertility in Chiang Mai had started to decrease before the programs started as well as during the initial years when acceptance was still low.

\section{SUMMARY AND CONCLUSIONS}

The analysis has revealed that during the period 1960-75 different patterns of fertility decline emerged in Chiang Mai Province, two of the three adjacent provinces, and Thailand as a whole. In Chiang Mai Province, the fertility level showed a rapid decline, especially after 1964; the total fertility rate declined by almost 50 percent between 1960 and 1975; the proportion of births of third or higher order decreased from 60.3 percent in 1964 to 24.3 percent in 1975; the age pattern of fertility in 1970 as compared with 1960 indicated that the fertility decline was particularly pronounced among older women, especially those above age 30 ; the fertility of both the rural population (with the exception of one remote area containing 7 percent of the total population) and the urban population (represented by Chiang Mai City, with 13.4 percent of the total population) appears to have started declining in the mid 1960s.

Fertility trends in Lamphun Province resemble those for Chiang Mai Province quite closely, but in Lampang Province the drop in fertility appears to have started later, and in Chiang Rai Province there is little evidence of fertility decline throughout the period of 1960-75. The findings of a modest decline in fertility between 1960 and 1970 for Thailand as a whole, and a more decisive decline thereafter, are supported by evidence from other sources.

With respect to causal factors, there is little evidence of much change in nuptiality patterns between 1960 and 1970 in the Chiang Mai and Lamphun populations. Modern contraceptive practice, however, has been spreading throughout the urban and rural areas of Chiang Mai and Lamphun Provinces since 1963, as indicated by acceptance of family planning programs. The proportion of new acceptors in the highest fertility age group (20-29) increased from 51 percent in 1970 to 67 percent in 1975. Injectable contraceptives are the most popular method. It is reasonable to conclude that the fertility decline in Chiang Mai and Lamphun Provinces during the period under study is in part at tributable to the acceptance by women of easily available family planning methods. 


\section{REFERENCES}

Brass, William

1968 The Demography of Tropical Africa. Princeton: Princeton University Press.

Chamratrithirong, Apichat

1976 Fertility, nuptiality and migration in Thailand, 1970 census: the multiphasic response theory. Unpublished Ph.D. dissertation, Brown University.

Chiang Mai Province, Chiang Mai Municipal Office

Undated Public health statistics 1956-1975. Unpublished data.

Chiang Mai Province, Office of Health

Undated Public health statistics 1956-1975. Unpublished data.

1976 Public health statistics 1947-1975. Unpublished manuscript.

Chiang Mai Province, Provincial Education Section

1974a Report on Educational Management and Primary School Statistics, Vol. 1.

1974b School survey data. Unpublished.

Coale, Ansley J., and T. James Trussell

1974 Model fertility schedules: variations in the age structure of childbearing in human populations. Population Index 40:185-258.

Knodel, John

1977 Family limitation and the fertility transition: evidence from the age patterns of fertility in Europe and Asia. Population Studies 31(2): 219-249.

Knodel, John, and Pichit Pitaktepsombati

1975 Fertility and family planning in Thailand: results from two rounds of a national study. Studies in Family Planning 6(11):402-413.

Knodel, John, and Visid Prachuabmoh

1974 Demographic aspects of fertility in Thailand. Population Studies 28(3):423-448.

Pardthaisong, Tieng; Edwin B. McDaniel; and Ronald H. Gray

1975 Acceptance and use of Depo Provera in Chiang Mai. IPPF Medical Bulletin 9(1). 
Pearl, Raymond

1937 Variation in parity of women bearing children in the U.S. Birth Registration Area in 1930. Human Biology 9:65-98, pt. 1.

Rungpitarangsi, Vichai

1974 Fertility in Thailand. Unpublished M.A. thesis, London School of Hygiene and Tropical Medicine, London University.

Thailand, Ministry of Public Health

1969 Monthly Report on Family Planning Acceptors: December. Bangkok: Family Planning Project.

1970 Monthly Report on Family Planning Acceptors: December. Bangkok: Family Planning Project.

1971 Monthly Report on Family Planning Acceptors: December. Bangkok: Family Planning Project.

1972a Family Planning in Thailand 1965-1971. Bangkok: National Fam. ily Planning Program.

1972b Monthly Report on Family Planning Acceptors: December. Bangkok: Family Planning Project.

1972c Public Health Statistics. Bangkok: Division of Vital Statistics, Department of Health Promotion.

1974 Annual Statistical Report. Bangkok: National Family Planning Program.

1976 Annual Statistical Report. Bangkok: National Family Planning Program.

Undated Public Health Statistics 1960-1975. Unpublished data. Division of Vital Statistics, Department of Health Promotion.

Thailand, Office of Prime Minister

1962 Thailand Population Census 1960: Whole Kingdom and Regional Series. Bangkok: National Statistical Office.

1970 The Report of the Survey of Population Change 1964-1967. Bangkok: National Statistical Office.

19731970 Population and Housing Census: Whole Kingdom and Regional Series. Bangkok: National Statistical Office.

1977 The Report of the Survey of Population Change 1974-1975. Bangkok: National Statistical Office. 


\section{CURRENTLY AVAILABLE PAPERS OF THE EAST-WEST POPULATION INSTITUTE}

No.

18 On aggregative economic models and population policy, by Geoffrey McNicoll, October $1971,87 \mathrm{pp}$.

19 Households, families and friends in a Hawaiian-American community, by Alan Howard, November $1971,117 \mathrm{pp}$.

23 A model for the age distribution of first marriage, by Griffith M. Feeney, April 1972, $31 \mathrm{pp}$.

27 Representation of national and regional political units in a computerized world future model, by Peter Maggs, October 1972, 51 pp.

28 The demographic situation in Indonesia, by Geoffrey McNicoll and Si Gde Made Mamas, December 1973,68 pp.

30 Demographic research in Japan, 1955-70: a survey and selected bibliography, by $Y$. Scott Matsumoto, April 1974, 88 pp.

32 The value of children in Asia and the United States: comparative perspectives, by James T. Fawcett et al., July 1974,80 pp.

33 The present and prospective state of policy approaches to fertility, by Ozzie G. Simmons and Lyle Saunders, June 1975, 32 pp.

$34 \mathrm{Female}$ labor force participation in a modernizing society: Malaya and Singapore, 19211957 , by Monica S. Fong, June 1975, 48 pp.

35 Fertility socialization research in the United States: a progress report, by Susan $O$. Gustavus, July 1975,28 pp.

36 Data relevant to socialization in the U.S. national fertility surveys, by Larry L. Bumpass, December $1975,20 \mathrm{pp}$.

37 Some sociological suggestions concerning the reduction of fertility in developing countries, by Norman B. Ryder, January 1976,20 pp.

38 Future autobiographies: expectations of marriage, children, and careers, by Nancy $E$. Williamson, Sandra L. Putnam, and H. Regina Wurthmann, February 1976, 36 pp.

39 The development of family size and sex composition norms among U.S. children, by Gerald E. Markle and Robert F. Wait, September 1976, 32 pp.

40 Urbanization in the Philippines: historical and comparative perspectives, by Ernesto M. Pernia, November 1976, $44 \mathrm{pp}$.

41 A method of decomposing urban population growth and an application to Philippine data, by Ernesto M. Pernia, Decem ber 1976, 32 pp.

42 Methodological difficulties encountered in using own-children data: illustrations from the United States, by Ronald R. Rindfuss, February 1977, 24 pp.

43 The fertility of migrants to urban places in Thailand, by Sidney Goldstein and Penporn Tirasawat, April 1977, 56 pp.

44 The demographic situation in the Philippines: an assessment in 1977, by Mercedes $B$. Concepción and Peter C. Smith, June 1977, 84 pp.

45 The demographic situation in Thailand, by Fred Arnold, Robert D. Retherford, and Anuri Wanglee, July $1977,44 \mathrm{pp}$.

46 The role of migration and population distribution in Japan's demographic transition, by Toshio Kuroda, July 1977, 24 pp. 
THE EAST-WEST CENTER-officially known as the Center for Cultural and Technical Interchange Between East and West-is a national educational institution established in Hawaii by the U.S. Congress in 1960 to promote better relations and understanding between the United States and the nations of Asia and the Pacific through cooperative study, training, and research. The Center is administered by a public, nonprofit corporation whose international Board of Governors consists of distinguished scholars, business leaders, and public servants.

Each year more than 1,500 men and women from many nations and cultures participate in Center programs that seek cooperative solutions to problems of mutual consequence to East and West. Working with the Center's multidisciplinary and multicultural staff, participants include visiting scholars and researchers; leaders and professionals from the academic, government, and business communities; and graduate degree students, most of whom are enrolled at the University of Hawaii. For each Center participant from the United States, two participants are sought from the Asian and Pacific area.

Center programs are conducted by institutes addressing problems of communication, culture learning, environment and policy, population, and resource systems. A limited number of "open" grants are available to degree scholars and research fellows whose academic interests are not encompassed by institute programs.

The U.S. Congress provides basic funding for Center programs and a variety of awards to participants. Because of the cooperative nature of Center programs, financial support and cost-sharing are also provided by Asian and Pacific governments, regional agencies, private enterprise, and foundations. The Center is on land adjacent to and provided by the University of Hawaii.

THE EAST-WEST POPULATION INSTITUTE, established as a unit of the East-West Center in 1969 with the assistance of a grant from the Agency for International Development, carries out multidisciplinary research, training, and related activities in the field of population, placing emphasis on economic, social, psychological, and environmental aspects of population problems in Asia, the Pacific, and the United States.

East-West Population Institute

East-West Center

1777 East-West Road

Honolulu, Hawaii 96848
Director Lee-Jay Cho Publications Officer Sandra $E$. Ward Editor Milann Gannaway Production Assistant Lois M. Bender Cartographer Gregory Chu 